\title{
Zooming into Real-Life Extraversion - how Personality and Situation Shape Sociability in Social Interactions
}

\author{
Simon M. Breil*, Katharina Geukes*, Robert E. Wilson+ ${ }^{\dagger}$, Steffen Nestler ${ }^{\ddagger}$, Simine Vazire \\ and Mitja D. Back*
}

\begin{abstract}
What predicts sociable behavior? While main effects of personality and situation characteristics on sociability are well established, there is little evidence for the existence of person-situation interaction effects within real-life social interactions. Moreover, previous research has focused on self-reported behavior ratings, and less is known about the partner's social perspective, i.e. how partners perceive and influence an actor's behavior. In the current research, we investigated predictors of sociable behavior in real-life social interactions across social perspectives, including person and situation main effects as well as person-situation interaction effects. In two experience-sampling studies (Study 1: $N=394$, US, time-based; Study 2: $N=124$, Germany, event-based), we assessed personality traits with self- and informant-reports, self-reported sociable behavior during real-life social interactions, and corresponding information on the situation (categorical situation classifications and dimensional ratings of situation characteristics). In Study 2, we additionally assessed interaction partner-reported actor behavior. Multilevel analyses provided evidence for main effects of personality and situation features, as well as small but consistent evidence for person-situation interaction effects. First, extraverts acted more sociable in general. Second, individuals behaved more sociable in low-effort/positive/low-duty situations (vs. high-effort/negative/high-duty situations). Third, the latter was particularly true for extraverts. Further specific interaction effects were found for the partner's social perspective. These results are discussed regarding their accordance with different behavioral models (e.g., Trait Activation Theory) and their transferability to other behavioral domains.
\end{abstract}

Keywords: Interpersonal behavior; Extraversion; Sociability; Person-by-situation Interaction; Situations

Individual differences in sociability-that is how much people like to be with and talk to other people (cf. McCrae $\&$ Costa, 1987)-have been related to a variety of important variables, including higher positive affect (Emmons \& Diener, 1986), higher political involvement (Foschi \& Lauriola, 2014), higher job performance (Barrick \& Mount, 1991; Hurtz \& Donovan, 2000), and higher life satisfaction (Emmons \& Diener, 1986). But why do people show differing levels of sociable behavior in real-life social interactions?

Imagine two students Andy and Patsy. Generally, Andy behaves more sociable than Patsy, while both tend to act more sociable during a party than during a study session. When Andy is going out to parties, however, he is the center of attention and excessively talks about his recent activities, while Patsy sits by herself most of the time, only interacting with a few other people. When in

\footnotetext{
* University of Münster, DE

+ University of California Davis, US

* University of Leipzig, DE

Corresponding author: Simon M. Breil (simon.breil@uni-muenster.de)
}

a study group though, Andy and Patsy are both modestly talkative. This example illustrates three potential effects on sociable behavior: Personality effects, situation effects, and personality-situation interaction effects.

Both personality and situations are discussed as predictors of sociable behavior (cf. Fleeson, 2007) and have been shown to independently predict observed behavior in the laboratory (e.g., Eaton \& Funder, 2003) as well as self-reported behavior in the field (e.g., Sherman, Rauthmann, Brown, Serfass, \& Jones, 2015). Although personality-situation interaction effects are at the core of theories on behavioral prediction (e.g., Lewin, 1951; Mischel \& Shoda, 1995; Tett \& Guterman, 2000), they were only seldom found (Ching et al., 2014; Sherman et al., 2015). Moreover, prior research has only occasionally analyzed sociable behavior in action, that is, during real-life social interactions. ${ }^{1}$ In the present research, we therefore aim at a detailed investigation of personality, situation, and interaction effects on sociable behavior, focusing on (a) whether established main effects of personality and situation replicate in real-life social interactions and (b) whether there are additional 
interaction effects. In doing so, we will explore sociable behavior across different social perspectives, moving beyond a sole focus on self-reported behavior.

\section{Predictors of Sociable Behavior}

Following classic concepts of behavior prediction that conceptualize behavior as a function of personality and environment (Lewin, 1951; Mischel \& Shoda, 1995; Tett \& Guterman, 2000), Andy's and Patsy's behaviors described above could be explained by (1) their personality (e.g., Andy is a sociable person, Patsy is a not so sociable person), (2) the situation they were in (e.g., the party situation, but not as much the study situation, calls for sociable behavior), and (3) an interaction between their personality and situational characteristics (e.g., Andy acts especially sociable in party situations but not in study situations). What is the empirical evidence for those three effects?

\section{Personality as a Predictor of Sociability}

There is compelling evidence that individual differences in personality traits predict differences in behavior (e.g., Back, Schmukle, \& Egloff, 2009; Borkenau, Mauer, Riemann, Spinath, \& Angleitner, 2004; Funder \& Colvin, 1991; Mehl, Gosling, Pennebaker, 2006; Vazire, 2010). In line with conceptualizations of trait extraversion that describe sociability as one important facet (e.g., DeYoung, Quilty, \& Peterson, 2007; John \& Srivastava, 1999), research has identified extraversion as the main predictor of sociable behavior (e.g., Eaton \& Funder, 2003; Fleeson \& Gallagher, 2009; Sherman et al., 2015). In a laboratory study, Eaton and Funder (2003) found that self-reported extraversion predicted observed sociability (e.g., is talkative, is reserved and unexpressive - negative) as was found in other laboratory studies (e.g., Back et al., 2009; Borkenau et al., 2004; Fleeson \& Law, 2015; McCabe \& Fleeson, 2016; Noftle \& Fleeson, 2010). Furthermore, Borkenau and colleagues (2004) showed that not only self-, but also informant-reported extraversion predicted behavior during laboratory based tasks.

There is also evidence that trait personality predicts behavior in real-life field settings. For example, in a metaanalysis consisting of 15 studies, Fleeson and Gallagher (2009) examined the relationship between Big Five traits and repeatedly assessed state measures (e.g., during the last hour, how talkative were you?). Trait extraversion predicted single state extraversion with an average correlation of .18 (average state extraversion $r=.42$ ). Similar results were found in a number of other experience-sampling studies focusing on (trait) extraversion (e.g., Bleidorn, 2009; Fleeson, 2001; Heller, 2007; McCabe \& Fleeson, 2012, 2016; Wilt, Noftle, Fleeson, \& Spain, 2012), and they replicated across cultures (Ching et al., 2014) and across different settings (work setting; Judge, Simons, Hurst, \& Kelly, 2014). An experience sampling study by Sherman and colleagues (2015) showed comparable results for the more specific state item outgoing/sociable assessed at multiple, random times each day. Additionally, in one of the first studies using the Electronically Activated Recorder (Mehl, Pennebaker, Crow, Dabs, \& Price, 2001), Mehl and colleagues (2006) reported significant associations between trait extraversion and talking as well as spending less time alone but not socializing. Still, all these findings clearly point to the important role of trait extraversion for the prediction of state extraversion and sociable behavior.

\section{Situation as a Predictor of Sociability}

Situation characteristics have also been shown to predict differences in behavior (e.g., Sherman et al., 2015). One important situational requirement for the occurrence of sociable behavior is the situation being embedded in a social context (i.e., with others), as individuals cannot vary in their sociability when not interacting with someone. Besides that, sociability is conceptually and empirically associated with positivity and pleasantness (e.g., Diener, Larson, \& Emmons, 1984; Lucas \& Diener, 2001; Rauthmann et al., 2014; Wilt et al., 2012) as well as a lack of tasks, clarity, and structures (Ching, 2014; Fleeson, 2007). In contrast to the conceptualization of personality, there is no consensus yet on how to best define and assess psychological situations (e.g., Hogan, 2009; Rauthmann, Sherman, \& Funder, 2015). However, scholars have offered two major complementary approaches to quantify situations within personality psychology: Situational categories and situational dimensions (cf. Rauthmann et al., 2015).

Situational categories are based on similar cues or profiles of characteristics within a situation, e.g., work situations or study situations (cf. Rauthmann et al., 2015). Many approaches that sort situations into categories should theoretically be associated with differences in sociable behavior, including work vs. recreation (Diener et al., 1984), social vs. nonsocial (Lucas \& Diener, 2001; Srivastava, Angelo, \& Vallereux, 2008), pleasure vs. individual adversity vs. interpersonal conflict vs. social demand (Ten Berge \& de Raad, 2002), active participation vs. social entertainment vs. social responsibility situations (Watson, Clark, McIntyre, \& Hamker, 1992; also see Lucas, Le, \& Dyrenforth, 2008), and hedonic situations (low-effort activities) vs. eudaimonic situations (high effort activities; Waterman (2005), see Oerlemans \& Bakker, 2014 for an implementation). Research focusing on the behavioral consequences of those categories and especially on sociable behavior has been quite rare. In a laboratory study by Funder and Colvin (1991), behavioral ratings for items such as is talkative or is expressive in face, voice, or gestures were lower in getting-to-know situations vs. serious debate situations, but higher for items more related to social behavior (e.g., initiated humor, smiles frequently). This shows a mixed pattern concerning the influence of structured and task-related categories on sociable behavior.

A second way to conceptualize situations is to use situational dimensions that capture the psychological meanings of perceived situational cues (Rauthmann et al., 2015). In contrast to situational categories, multiple situational dimensions are measured in a continuous fashion (e.g., Riverside Situational Q-Sort; RSQ; Wagerman \& Funder, 2009). Recently, Rauthmann and colleagues (2014; see also Rauthmann \& Sherman, 2016a) identified eight dimensions in the RSQ: The situational eight DIAMONDS. Those dimensions are: duty (work has to be done), intellect (deep thinking is required), adversity (somebody is being threatened, accused, or criticized), mating (potential romantic partners are present), positivity (the situation is pleasant), negativity (the situation contains negative 
feelings), deception (somebody is being deceived), and sociality (social interactions are possible or required). In a first field study using the DIAMONDS dimensions, Sherman et al. (2015) found that self-reported sociality of a given situation predicted self-reported sociable behavior. This holds for sociability within persons (e.g., Andy acts more sociable in party than in study situations) and between persons (e.g., people who experience more party situations behave more sociable). Additionally, in experience-sampling studies by Fleeson (2007) and Ching et al. (2014), the situational dimensions low taskorientation (e.g., obligations), friendliness of interaction partners, low anonymity, others' status, and perceived autonomy predicted self-reported extraverted behavior.

Based on these result, and beyond the social context, people should act more sociable in situations with positive social cues and generally less sociable in situations that are associated with tasks and obligations. For this research, we decided to include both, more objective situational categories as well as situational dimensions, for a comprehensive situational approach.

\section{Personality - Situation Interaction as a Predictor of Sociability}

To date, most researchers agree that personality as well as situations are both relevant predictors of behavior (e.g., Fleeson \& Noftle, 2009; Sherman et al., 2015) and it has been shown that sociable behavior in particular is predicted by both situations and personality (e.g., Ching, 2014; Fleeson, 2007; Fleeson \& Gallagher, 2009; Sherman et al., 2015). It is, however, less clear whether there are personsituation interaction effects that work in addition to these two main effects. Interaction effects, for instance, would describe the degree to which being extraverted and being in a specific situation provokes particularly strong sociable behavior, above and beyond what would be expected from each of the main effects (of the person and the situation; for overviews of interactional perspectives see: Endler \& Edwards, 1986; Endler \& Magnusson, 1976; Snyder \& Ickes, 1985). Thus, interaction effects describe the theoretical assumptions that the influence of a situation on sociable behavior differs between extraverts and introverts (i.e., for different levels of extraversion) or that the influence of personality on sociable behavior differs between different situations and for different levels of situational dimensions.

Such interaction effects are predicted by several models. For example, Trait Activation Theory (TAT; Tett \& Burnett, 2003; Tett \& Guterman, 2000) postulates situations as moderators of the relationship between personality (e.g., extraversion) and trait-related behavior (e.g., sociable behavior). Thus, if a situation is relevant to a trait (i.e., provides cues for the expression of trait-relevant behavior), trait-relevant behavior should be expressed (also see Lievens, Chasteen, Day, \& Christiansen, 2006). In a related way, Cognitive-Affective Processing System model (CAPS; Mischel \& Shoda, 1995; Mischel \& Shoda, 2008) proposes that individual differences in behavior can be explained by individual differences in the strength of situation-based behavioral contingences (i.e., if-then patterns; e.g., if Andy is in a party situation, then he behaves very sociable, but if Patsy is in a party situation, then she behaves less sociable).
Here, situation effects on behavior are moderated by some sort of person characteristic. CAPS would, for instance, predict that goals that are characteristic for extraversion (e.g., connecting with people, having fun with people) moderate the effect of situational features on sociable behavior. Whole Trait Theory (WTT; Fleeson \& Jayawickreme, 2015) focuses on density distributions of states when describing behavior, with the mean level of states corresponding to one's trait level. Regarding our example, this would mean that, on average, extraverts act more sociable than introverts, and situations explain deviations from this central tendency. While other theories focus more directly on person-situation interaction effects, they could also be in incorporated in WTT: If there are interaction effects, extraverts and introverts, would for example, deviate systematically differently from their central tendencies depending on situational features.

The empirical evidence for person-situation interaction effects is mixed. While there is evidence of personsituation interaction effects in a variety of areas (e.g., Haaland \& Christiansen, 2002; Lievens et al., 2006; Tett \& Burnett, 2003; see Lakey 2016 for an overview of interaction effects in different areas) there is currently little evidence for interaction effects when it comes to experience-sampled everyday behaviors. In two of the few studies that simultaneously investigated personality and situational determinants of everyday behavior, Ching et. al. (2014) and Sherman et al. (2015) report independent effects for extraversion and situation (autonomy and sociality) but no significant interaction effects.

\section{Sociable Behavior Across Social Perspectives}

One of the goals of this research was to move beyond a pure focus on self-reports when investigating sociable behavior. So far, most previous research has considered the determinants of sociable (or more generally: extraverted) behavior in real-life from the perspective of one individual, involving self-reported sociable behavior predicted by self-reported personality and self-reported situations. However, sociable behavior revolves around interacting with other people. In fact, sociable behaviors within a social interaction are performed and perceived by all individuals involved. That is, an individual within a social interaction is not only an actor showing behavior but also a partner towards whom others act. In addition, all behaviors (of the actor and of the interaction partners) are perceived by the actor him-/herself and the interaction partners (also see Back \& Kenny, 2010; Back et al., 2011; Back, 2015; Back \& Vazire, 2015; Kenny, Mohr, \& Levesque, 2001; Schaffhuser, Allemand, \& Martin, 2014; Slatcher \& Vazire, 2009). Thus, if one considers a social interaction between two partners, there are four possible perspectives (excluding meta-perceptions) regarding effects of personality on behavioral assessments (see Table 1).

Perspective 1 involves the effect of an actor's personality on his self-reported behavior (i.e., self-reported behavior; e.g., Does Andy's extraversion predict how sociable he perceives his own behavior?), which was extensively described above. Perspective 2 involves the effect of an actor's personality on his behavior as perceived by his interaction partner (i.e., interaction partner-reported actor behavior; e.g., Does 
Table 1: Overview Perspectives, Hypothesis and Exploratory Questions, and Results.

\begin{tabular}{llll} 
Perspective & $\begin{array}{l}\text { Relevant } \\
\text { Question }\end{array}$ & $\begin{array}{l}\text { Relevant } \\
\text { variables }\end{array}$ & $\begin{array}{l}\text { Hypotheses/Exploratory Results } \\
\text { Questions }\end{array}$ \\
\hline
\end{tabular}

\begin{tabular}{|c|c|c|c|c|}
\hline $\begin{array}{l}\text { Perspective } 1 \\
\text { (self-reported } \\
\text { behavior) }\end{array}$ & $\begin{array}{l}\text { Does an actor's } \\
\text { personality predict } \\
\text { how he perceives } \\
\text { his own behavior? }\end{array}$ & Actor extraversion & $\begin{array}{l}\text { Actor's extraversion predicts } \\
\text { actor's self-reported } \\
\text { sociable behavior }\end{array}$ & $\begin{array}{l}\text { Prediction supported: Actor's } \\
\text { extraversion predicts actor's self- } \\
\text { reported sociable behavior }\end{array}$ \\
\hline
\end{tabular}

Self-reported actor behavior

Exploratory: Possible interaction effects regarding actor extraversion and type of situation

$\begin{array}{ll}\text { Actor extraversion } & \text { Actor's extraversion predicts } \\ & \text { partner-reported sociable } \\ & \text { actor's behavior }\end{array}$

Interaction Exploratory: Possible partner-reported actor behavior

interaction effects regarding actor extraversion and type of situation

$\begin{array}{ll}\text { Perspective 2 } & \text { Does an actor's } \\ \text { (interaction } & \text { personality } \\ \text { partner-reported } & \text { predict how he } \\ \text { actor behavior) } & \begin{array}{l}\text { is perceived by } \\ \text { a partner? }\end{array}\end{array}$

Does a partner's Partner

Perspective 3 (perceiver effects) personality predict extraversion how she perceives an actor?

Interaction partner-reported actor behavior

Perspective 4 (evoked behavior)

\author{
Does a partner's Partner \\ personality predict extraversion \\ how an actor \\ perceives his \\ own behavior?
}

Self-reported actor behavior
Exploratory: Relationship between partner's extraversion and partner-reported sociable actor's behavior

Exploratory: Possible interaction effects regarding actor extraversion, partner extraversion, and/or type of situation

Exploratory: Relationship between partner's personality and actor's selfreported sociable behavior

Exploratory: Possible interaction effects regarding actor personality, partner personality, and/or type of situation

\section{The influence of situation (low-effort vs. high-effort, duty, positivity vs. negativity) on actor's self-reported behavior was moderated by actor's personality}

\section{Prediction supported: Actor's extraversion predicts partner-reported sociable actor's behavior
The influence of situation (low-effort vs. high-effort, duty, positivity vs. negativity) on partner-reported sociable actor's behavior was moderated by actor's personality

\section{Mixed results: Significant main effect for partner's personality and partner-reported sociable actor's behavior in 1 of 4 models.}

The influence of actor's
extraversion on partner-
reported actor's sociable
behavior was moderated by
partner's extraversion
No main effect for partner's
personality and actor's self-
reported sociable behavior
The influence of situation
(low-effort vs. high-effort
sociality, positivity vs. negativity)
on actor's self-reported
behavior was moderated by
partner's extraversion

The influence of actor's behavior was moderated by No main effect for partner's personality and actor's self-
Andy's extraversion predict how sociable his behavior is perceived by Patsy?). Perspective 3 involves the effect of a partner's personality on her perceptions of the sociability of others' behaviors (i.e., perceiver effects; e.g., Does Patsy's extraversion predict how sociable she perceives Andy's behavior?). Perspective 4 involves the effect of a partner's personality on self-reported actor behavior (i.e., evoked behavior; e.g., Does Patsy's extraversion predict how sociable Andy perceives his own behavior?).

These perspectives can be applied to all kinds of possible main effects of personality and situation characteristics as well as person-situation interaction effects on sociable behavior. To give some examples: Patsy might perceive Andy as more sociable in party situations than in study situations (Perspective 2). An extraverted perceiver might perceive Andy as especially sociable (Perspective 3). Andy might perceive himself as sociable when he is around extraverted people but particularly in specific situations (Perspective 4). In addition, there could also be interaction effects between actor and partner extraversion and selfand/or interaction partner-reported actor behavior (e.g., If Andy and Patsy are both extraverts, they both perceive themselves and/or each other as especially sociable.).

While there have been studies considering similar perspectives in other contexts (e.g., relationship satisfaction; Schaffhuser et al., 2014), to the best of our knowledge, effects of personality traits on sociable behavior have not yet been examined across these four perspectives 
in a real-life context. In a laboratory study by Eaton and Funder (2003), participants engaged in 5 minutes of social interactions that were video-taped, uninvolved observers as well as interaction partners rated participants' behavior. Results show that self-reported extraversion predicted observed sociable behavior (Perspective 2). However, the partner's extraversion did not predict partner's perception of actor's sociable behavior (Perspective 3) and, although partner's extraversion predicted some actor's behaviors (Perspective 4; for example, expresses agreement frequently, seems to like partner), sociable behavior was not predicted by partner's extraversion.

\section{Challenges}

While all the previously mentioned studies have provided important insights on the determinants of sociable behavior, a number of extensions seem promising to further understand the link between personality, situations, and real-life sociable behavior.

First, apart from the studies by Mehl et al.(2006), Sherman et al. (2015), and McCabe and Fleeson (2016) there is, to our knowledge, no research specifically investigating the influence of extraversion on sociable behavior in real-life situations. Most field studies have relied on state extraversion questionnaires focusing on one broad construct. Thus, to allow for robust insights, more research is needed on the determinants of real-life sociable behavior in particular.

Second, most of the previous field studies relied on global, time-based experience sampling. Participants retrospectively reported on their behavior during the day or the last hour(s). This procedure has the advantage of sampling across a larger time period for each assessment, thereby increasing the probability of including relevant behaviors; it might, however, involve retrospective biases (Bolger, Davis, \& Rafaeli, 2003). One alternative is to ask for current state expressions in random intervals (e.g., Sherman et al., 2015). This procedure circumvents retrospective biases but might miss relevant situations and behaviors between assessments. Another option that has not yet been applied in the study of sociable behavior is an event-based experience sampling approach that is directly asking for state expressions after specified events. Given that sociable behavior revolves around interactions with other people, such an event-based, i.e., social interactionbased, approach seems to be particularly fruitful for the study of real-life sociability (i.e., measuring sociable behavior contingent on the presence of other people).

Third, previous field studies have focused on selfreported personality traits and self-reported behavior. While this in itself is an important contribution, potential method overlap between self-reports might lead to overestimations of effect sizes (Back \& Egloff, 2009). In addition, there are informational and motivational limits in self-reports (Back \& Vazire, 2012; Gosling, John, Craik, \& Robins, 1998; John \& Robins, 1994) and studies show that close others are as accurate as the self in predicting behavior (e.g., Kolar, Funder, \& Colvin, 1996; Vazire, 2010; Vazire \& Mehl, 2008). Thus, informantreports of personality as well as interaction partner-reports of actor behavior are a valuable addition when it comes to investigating predictors of sociable behavior.

Fourth, considering possible person-situation effects, previousstudies havesolely focused on self-rated perceptions of situations (e.g., Ching et al., 2014; Fleeson, 2007; Sherman et al., 2015). If a person, however, simultaneously reports his perception of a situation, his behavior, and his personality, high correlations between those variables are likely due to method overlap, which reduces the chance to find meaningful person-situation interaction effects. Thus, a more objective classification and/or rating of situations that is methodologically independent of the personality and behavioral reports might help to reveal meaningful person-situation interactions.

Fifth, as previously mentioned, sociable behavior by definition is only possible when interacting with others. However, previous research (e.g., Ching et al., 2014; Fleeson, 2007; Fleeson \& Gallagher, 2009; Sherman et al., 2015) has not differentiated between situations with or without possible social interaction. Thus, it could be the case that situations relevant to a trait were not assessed with the required specificity. Including contexts in which sociable behavior was not possible might have underestimated possible person-situation interaction effects. The activation of sociable behaviors by specific situational characteristics in some but not all people (cf. TAT; Tett \& Guterman, 2000) might only be revealed when specific situational dimensions and person differences are considered within the overall context of social interaction (i.e., extraversion differences are activated by certain situational features but only in social interactions). It would, therefore, be beneficial to specify the general context (i.e., social interaction) and focus on specific situation dimensions and categories within this context.

Sixth, the influence of sociable behavior across social perspectives (influence and perception of interaction partners) is understudied. While previous laboratory research(Eaton \&Funder,2003)didnotsupportextraversion effects for Perspectives 3 (perceiver effects) and 4 (evoked behavior) on sociable behavior, additional and especially field-based research is needed. Sociable behavior in reallife social interactions might differ from laboratory settings as people face real consequences (Fleeson \& Gallagher, 2009). Furthermore, the inclusion of personality-situation as well as actor-partner personality interaction effects are promising additions to the comprehensive investigation of sociable behavior across social perspectives.

\section{The Present Research}

The aim of the current research was to investigate predictors of sociable behavior in real-life social interactions, including person and situation main effects as well as person-situation interaction effects. In doing so, we applied a multi-methodological approach to the assessment of personality (self- and informant-reports) and situations (dimensional and categorical measures). We used data from two experience sampling studies (Study 1: time-based; Study 2: event-based) that both employed a rich multimethod longitudinal design. We assessed self-reported sociable behavior (both studies) as well as interaction 
partner-reported sociable actor behavior (Study 2) in reallife social interactions, which made it possible to investigate behavior across the four different social perspectives.

The following hypotheses refer to self-reported sociable behavior and apply to both studies. Hypotheses regarding the other three social perspectives can be found in the introduction to Study 2 . Note that we did not register these hypotheses prior to data collection and analyses, and so all results should be interpreted with less confidence than if the hypotheses had been registered.

First, and in line with previous studies (e.g., Ching et al., 2014; Fleeson \& Galagher, 2009; Sherman et al., 2015), we expected to find main effects of extraversion (self- and informant-reported) on sociable behavior in daily life.

Second, we expected to find main effects of situations on sociable behavior. In contrast to previous studies, we decided to solely focus on situations in which social interaction took place and included both distinct categories and dimensional situational ratings. Specifically, we predicted that we would find main effects for low-effort (vs. high-effort; i.e., situations in which physical or mental activity is needed to achieve something) situational categories (more sociable behavior in low-effort categories). This was based on the idea that situations low in effort should be less structured around a specific topic, should provide more sociability related cues, and should involve less compulsory and often pre-scripted social interaction. Indirect evidence for the relation of effortlessness and sociability stems from research showing that individual differences in extraversion are related to differences in self-reported hedonism (i.e., tendency to gravitate towards life's pleasures e.g., Ksendzova, Iyer, Hill, Wojcik, \& Howell, 2015; Visser \& Pozzebon, 2013; Wilson \& Brazendale 1973; Zhang \& Howell, 2011) which should be rather pursued in low-effort compared to high-effort situations (cf. Watermann, 2005). Moreover, we expected to replicate findings of Sherman et al. (2015) for the DIAMONDS dimension sociality (more sociable behavior in situations high in sociality) and we took an exploratory approach towards those DIAMONDS dimensions that are theoretically and empirically connected to sociable behavior (i.e., positivity, negativity, duty).

Third, although previous research did not find personsituation interaction effects (Ching et al., 2014; Sherman et al., 2015), we took an exploratory approach towards possible interactive effects predicting sociable behavior. Focusing on situational differences within social interactions and using more objective/observer-rated situations might constitute two important conditions under which additional interaction effects might be revealed. If we find personsituation interaction effects, we would expect them to be in the direction that the difference between introverts and extraverts in sociable behavior should be especially pronounced in situations that provide cues for sociable behavior (e.g., low-effort situations).

\section{Study 1}

Study 1 uses data from the first wave of the longitudinal Personality and Interpersonal Roles Study (PAIRS; Vazire, Wilson, Solomon, Bollich, Harris, Weston, Mike, \& Jackson, 2015), which took place at Washington University in
St Louis, USA. For this study, a time-based experience sampling design (ESM) was used. In the following and the detailed documentations we are referring to, we report how we determined our sample size, all data exclusions, and all variables assessed as part of this project (cf. Simmons et al., 2012; see complete PAIRS documentations in the OSF: osf.io/akbfj for additional details regarding procedures and other measures collected). Analyses from this dataset have been published elsewhere (Beck \& Jackson, 2018; Colman, Vineyard, \& Letzring, 2017; Edwards \& Holtzman, 2017; Finnigan \& Vazire, 2017; Solomon \& Vazire, 2014; Sun, Schwartz, Son, Kern, \& Vazire, 2018; Sun \& Vazire, 2018; Wilson, Harris, \& Vazire, 2015; Wilson, Thompson, \& Vazire, 2017), but none of the presented results reported here overlap with any of the other published work.

\section{Method}

Participants. An initial sample of 434 students was recruited via the psychology participant pool, flyer advertisements, and classroom announcements. Out of those 434 participants who completed the first session, 394 (267 female; 125 male) completed all relevant measures for this study. Age ranged from 18 to 32 $(M=19.33, S D=2.04)$, participants received $\$$ US20 for participation in the laboratory portion of the first wave of the study, and could win \$US100 in a lottery for completing the experience sampling portion of the study. Data collection and analysis procedures were approved by the Institutional Review Boards at Washington University in St. Louis (IRB ID: 201206090) and the University of California, Davis (IRB ID: 669518-15).

Procedures. The first phase of the study involved a twohour lab session in which participants completed a variety of personality questionnaires, informant nominations, and a range of other tasks not related to the current study. During the two-hour lab session, participants were asked to nominate up to 10 informants to rate their personality on the same scales. A total of 1,279 informant-reports $(M=3.25$ per participant; $S D=1.87)$ were provided.

After completing the in-lab phase of the study, ESM surveys were emailed to the participants four times per day (12pm, 3pm, 6pm, 9pm) for 15 days (three times on the first day), resulting in a potential total of 59 surveys per participant. They were asked to rate how they were thinking, feeling, and behaving during the last hour block (e.g., from 8pm-9pm, were you...). Additionally, items about specific aspects of the situations were included. The questions could be completed on a smartphone or any other device connected to the internet and took 3 to 4 minutes to complete. A detailed overview of the ESM survey can be found on the PAIRS project page (osf.io/akbfj).

A total of 15,563 surveys were completed by participants and a number of exclusion criteria were used. Surveys were excluded when they were completed more than three hours after they were sent, when participants indicated that they were sleeping, when less than 75\% of the survey was completed, and when participants gave the same response for $70 \%$ or more of the items. This resulted in 11,591 surveys (cf. Wilson et al., 2015 regarding these exclusion criteria). Additionally, as the study revolves around sociable behavior, only surveys 
in which participants indicated they were interacting with other people were included (i.e., 3,073 exclusions, $27 \%$ ). Furthermore, surveys with missing situational information were excluded (33 exclusions). Applying these criteria leaves a total of 8,485 surveys. On average, each participant provided 21.54 surveys $(S D=11.96 ; M d n=20$; range: $1-54$; days with survey entries: $M=9.82 ; S D=3.79$; $M d n=10$; range $1-15)^{2}$ that were included.

\section{Measures}

Extraversion. To measure extraversion the Big Five Inventory was used (BFI-44; John \& Srivastava, 1999). Itemswere presented on a 15-point Likert-typescale ranging from disagree strongly to agree strongly. The agreement between self-ratings and averaged informant-ratings for extraversion was $r=.68$. Cronbach's alpha was .90 for self-ratings and .87 for informant-ratings. An aggregated extraversion score was computed by using the mean of the self- and the average informant-ratings.

Sociable Behavior. Self-reported behavior was measured by using a shortened version of the BFI-44 measure with two items per trait in the Experience Sampling questionnaire (for further information see Wilson et al., 2015). The behavior 'outgoing, sociable' was assessed on a five-point Likert scale ranging from 1 (not at all) to 3 (somewhat) to 5 (very) with the question: From [e.g., $8 p m-9 p m]$, were you... outgoing, sociable?

Situational assessments. Situational information was assessed with an open answer format in the Experience Sampling questionnaire: In a few words, what were you doing from (e.g., 8pm-9pm)? There was no limitation regarding the number of words or sentences. As we aimed for a comprehensive situational approach, we decided to use both, situational categories as well as situational dimensions.

Categorical Situational Codings. All open answers for the situations (e.g., "I was in French class", "I was eating with my boyfriend") were coded by three trained independent raters. First, the raters assigned specific situation categories to each open answer. Situation categories were taken from the CONNECT study (Study 2 in this paper) and included for example party situations, studying situations, or watching TV situations (Geukes, Breil, et al., 2017; Geukes, Hutteman, Nestler, Küfner, \& Back, 2018; see Table $\mathbf{2}$ for a full list of situation categories). Because there were some responses that did not fit into those existing categories, two additional categories (work and other) were added. Some hour blocks included more than one situation (e.g., in class, then watching TV), those hour blocks were sorted into multiple categories. For $97 \%$ of those surveys, at least two of the three raters agreed on the situation categories for each report. The remaining surveys (without consensus) were excluded from further analyses regarding those categories.

Additionally, the situation categories were sorted into two broader categories: ${ }^{3}$ Low-effort situations and higheffort situations (i.e., physical or mental activity needed to achieve something). Those categories were based on a study by Waterman (2005; for additional implementation see Oerlemans \& Bakker, 2014) who, within a sample of college students, identified specific activities that were rated low in effort (e.g., social activities, recreational activities) and high in effort (e.g., work activities, athletic activities). Building on these examples, we formed our categories. We chose this classification as a parsimonious approach that focuses on differences within (generally pleasurable) social activities that might be associated with differences in sociable behavior. Some situations did not fit into either class (e.g., on the phone) or had situations out of both categories (e.g., study then party) and were therefore excluded. The number of surveys that exclusively fit into one of those two categories was 7,250 (85\%). See Table 2 for an overview of all situations as well as their categorization.

Dimensional situational ratings. The independent raters also rated each open answer on all eight DIAMONDS dimensions (i.e., duty, intellect, adversity, mating, positivity, negativity, deception, sociality) using the S8-II short version DIAMONDS questionnaire (Rauthmann \& Sherman, 2016b) with seven-point Likert scales from 1 (does not apply at all) to 7 (applies perfectly). For further analyses, the mean rating of those three raters was used. For descriptive statistics and ICCs (ranging from .40 to .95), please refer to Table 2. Based on the ICCs as well as on theoretical and empirical associations with sociable behavior (e.g., Ching et al., 2014; Diener et al., 1984; Fleeson, 2007; Lucas \& Diener, 2001; Sherman et al., 2015), we decided to focus on four of the DIAMONDS dimensions: Sociality (i.e., social interactions are possible or required), duty (i.e., work has to be done), positivity (i.e., the situation is pleasant), and negativity (the situation contains negative feelings), as these likely consisted of aspects that might evoke intra- and interindividual differences in sociable behavior. Results for all DIAMONDS dimensions can be found in the online supplement. Due to the high correlation ( $r=-.92$ for the averaged codings) between positivity and negativity, we computed one positivity vs. negativity score (negativity ratings subtracted from positivity ratings) for a more parsimonious and less redundant representation of situational ratings.

Analytic strategy. As the experience sampling data were nested within persons, ${ }^{4}$ we used multi-level analyses to examine our research questions. In this model, participants' self-rated sociability ratings were predicted by the respective situation variable, the extraversion of participants and an extraversion-situation interaction variable. The estimated model (see Raudenbush \& Bryk, 2002; Nezlek, 2011) was

$$
\begin{aligned}
\text { Level 1: } & y_{i j}=\beta_{0 j}+\beta_{1 j}(\text { sit })+\varepsilon_{i j} \\
\text { Level 2: } & \beta_{0 j}=\gamma_{00}+\gamma_{01}(\text { ext })+\gamma_{02}\left(\text { sit }_{\text {mean }}\right)+u_{0 j} \\
& \beta_{1 j}=\gamma_{10}+\gamma_{11}(\text { ext })+u_{1 j}
\end{aligned}
$$

where $y_{\mathrm{ij}}$ denotes the sociability rating of person $i$ in situation $j$, situation is the respective situation variable, and extraversion refers to the extraversion values of the participants. To account for the fact that situation effects could manifest within as well as between persons, situation was within-person centered (Level 1) and each participant's average situation experience was added as an additional predictor at Level 2 (called sit ${ }_{\text {mean }}$ in Equation 1). For ease of interpretation, both Level 2 predictors were 


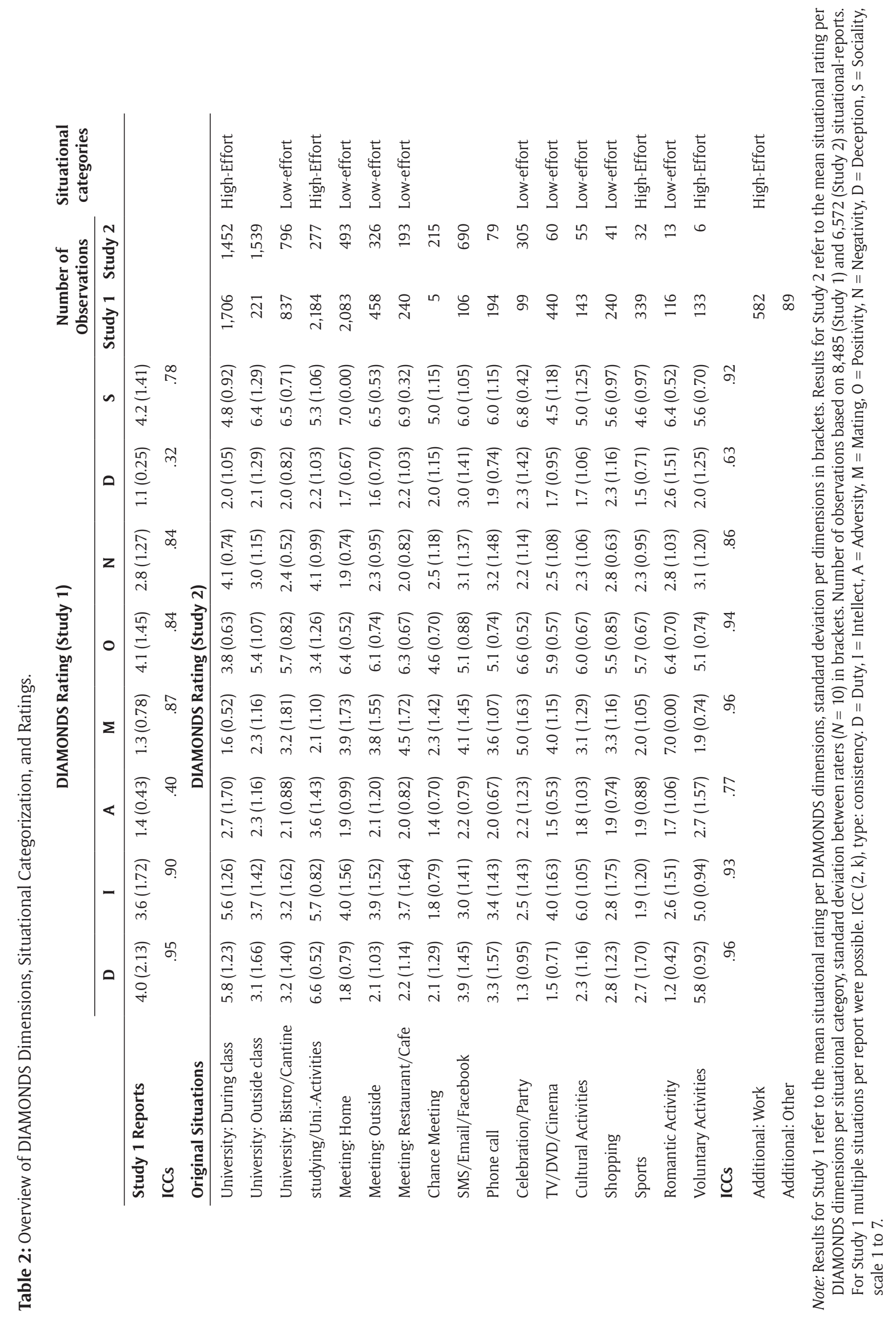


centered and extraversion was also standardized (cf. Nezlek, 2011). Taking into account the four different situation variables (i.e., 1: sociality; 2: duty; 3: positivity vs. negativity; 4: low-effort vs. high-effort), a total of four different models ${ }^{5}$ were estimated.

\section{Results}

Descriptive statistics and intercorrelations for relevant variables are shown in Table 3. For multi-level analyses we used the R packages lme4 (Bates et al., 2018) and lmerTest (Kuznetsova, Brockhoff, \& Christensen, 2018; $\mathrm{R}$ version 3.4.3; see osf.io/w96mv for data and R-code). Before focusing on the individual predictors, we assessed the proportion of variability in sociable behavior that is between versus within persons. For this purpose, a multilevel null model with sociable behavior as the dependent variable was estimated. The percentage of between-person variance (ICC) was $14 \%$ of total variance. This result shows that $14 \%$ of the variance in sociable behavior is at the between-person level and $86 \%$ of the variance is at the within-person level (though the within-person variance also contains all variance due to random error). Further results can be found in Table 4. Results of the four models are displayed in Table 5. Additional results containing the random effects, the remaining DIAMONDS dimensions, as well as separate self- and informant extraversions-ratings for the four models can be found in the online supplement (osf.io/w96mv). See Table 1 (Perspective 1) for a summary of predictions and results and Figure $\mathbf{1}$ for a graphic representation of selected results.

Perspective 1. Trait extraversion was significantly related to self-reported sociable behavior $\left(\gamma_{01}=.20\right.$, $p<.001){ }^{6}$ That is, extraverted people reported acting outgoing and sociable more than introverted people. Regarding between-person differences in situation experience, the situation's level of sociality significantly predicted sociable behavior $\left(\gamma_{02}=.25, p<.001\right)$. There was, however, no significant prediction for loweffort vs. high-effort situational categories as well as for duty and positivity vs. negativity situational dimensions. Therefore, people who on average experienced more situations with a high score in sociality, also reported (on average) more sociable behavior, but overall individual differences in experiencing more low-effort

Table 3: Means, Standard Deviations, and Intercorrelations of Self-Reported Sociable Behavior, Extraversion and Situational Variables (Study 1).

\begin{tabular}{lcccccccccc} 
& $\mathbf{N}$ & $\mathbf{M}$ & $\mathbf{S D}$ & $\mathbf{2}$ & $\mathbf{3}$ & $\mathbf{4}$ & $\mathbf{5}$ & $\mathbf{6}$ & $\mathbf{7}$ & $\mathbf{8}$ \\
\hline 1 Self-Reported Sociable Behavior (ESM) & 394 & 3.21 & 0.51 & $\mathbf{. 4 2}$ & $\mathbf{. 4 3}$ & $\mathbf{. 3 1}$ & .03 & $\mathbf{. 2 8}$ & .00 & .05 \\
2 Aggregated Extraversion & 394 & 9.57 & 2.33 & & $\mathbf{. 9 4}$ & $\mathbf{. 8 9}$ & -.01 & .08 & .01 & -.02 \\
3 Self-reported Extraversion & 391 & 9.14 & 2.84 & & & $\mathbf{. 6 8}$ & -.04 & .05 & .04 & -.07 \\
4 Informant-reported Extraversion & 366 & 10.06 & 2.11 & & & & .03 & .07 & -.04 & .05 \\
5 Low-effort vs. High-effort (ESM-coded) & 394 & 0.45 & 0.20 & & & & & $\mathbf{. 4 3}$ & $\mathbf{- . 9 2}$ & $\mathbf{. 8 3}$ \\
6 Sociality (ESM-coded) & 394 & 4.15 & 0.50 & & & & & & $\mathbf{- . 4 4}$ & $\mathbf{. 5 7}$ \\
7 Duty (ESM-coded) & 394 & 3.99 & 0.81 & & & & & & &.- .91 \\
8 Positivity vs. Negativity (ESM-coded) & 394 & 4.69 & 0.47 & & & & & & &
\end{tabular}

Note: ESM and ESM-coded variables were measured at level 1 (within-person, numbers of observations: 8,485 for self-reported sociable behavior and situational dimensions; 7,250 for situational categories), extraversion variables were measured at level 2 (between-person). Sociable behavior was reported on a 1 to 5 scale. Extraversion aggregate $=$ mean of self-reported and mean informant-reported extraversion. Extraversion was reported on a 1 to 15 scale. Low-effort vs. High-effort categories were coded based on open-ended ESM responses as: 1 = Low-effort; 0 = High-effort. Sociality, duty, and positivity vs. negativity were coded based on open-ended ESM responses, on a 1 to 7 scale. All means, standard deviations, and correlations are at the between-person level. Significant correlations $(p<.05)$ are in bold.

Table 4: Null Model with Random Effect Variances, ICCs, and Intercepts for Self- and Interaction Partner-Reported Sociable Actor Behavior (Study $1 \& 2$ ).

\begin{tabular}{|c|c|c|c|c|c|c|}
\hline & $\tau 00 a$ & $\tau 00 p$ & $\sigma^{2}$ & ICC & Int & $n$ \\
\hline Self-reported Sociable Behavior (Study 1) & 0.18 & - & 1.10 & $14 \%$ & 3.21 & 8,485 \\
\hline Self-reported Sociable Behavior (Study 2) & 0.29 & - & 0.65 & $33 \%$ & 5.64 & 6,572 \\
\hline Partner-reported Sociable Actor Behavior (Study 2) & 0.08 & 0.28 & 0.71 & $34 \%$ & 5.73 & 10,893 \\
\hline
\end{tabular}

Note: $N=394$ (Study 1), 122 (Study 2, self-reported behavior), 124 (Study 2, partner-reported actor behavior). Sociable behavior scale 1 to 5 (Study 1), 1 to 7 (Study 2). $\tau 00 \mathrm{a}$ = between-person variance for actor. $\tau 00 \mathrm{p}=$ between-person variance for partner. $\sigma^{2}=$ within-person variance (including random error). ICC = percentage of total variance that is between-person. Int $=$ fixed effects intercept. $n=$ number of observations. 
Table 5: Fixed Effects for Multi-Level Models: Predicting Self-Reported Sociable Behavior from Extraversion, Situation, and their Interaction (Study 1).

\begin{tabular}{|c|c|c|c|c|c|}
\hline Situation & Variable & $\boldsymbol{b}$ & SE & $95 \% \mathrm{CI}$ & $p$ \\
\hline \multirow[t]{5}{*}{ Low-effort vs. High-effort } & Intercept & 3.20 & .02 & {$[3.16,3.25]$} & $<.001$ \\
\hline & Extraversion (b) & .20 & .02 & {$[.15, .25]$} & $<.001$ \\
\hline & Situation $(w)$ & .48 & .03 & {$[.41, .54]$} & $<.001$ \\
\hline & Situation (b) & .15 & .13 & {$[-.10, .40]$} & .233 \\
\hline & Situation $(w) \times$ Extraversion $(b)$ & .08 & .03 & {$[.02, .15]$} & .013 \\
\hline \multirow[t]{5}{*}{ Sociality } & Intercept & 3.21 & .02 & {$[3.16,3.25]$} & $<.001$ \\
\hline & Extraversion (b) & .20 & .02 & {$[.15, .24]$} & $<.001$ \\
\hline & Situation (w) & .30 & .01 & {$[.28, .32]$} & $<.001$ \\
\hline & Situation (b) & .25 & .05 & {$[.16, .34]$} & $<.001$ \\
\hline & Situation $(w) \times$ Extraversion $(b)$ & .01 & .01 & {$[-.01, .03]$} & .144 \\
\hline \multirow[t]{5}{*}{ Duty } & Intercept & 3.21 & .02 & {$[3.17,3.25]$} & $<.001$ \\
\hline & Extraversion (b) & .21 & .02 & {$[.16, .25]$} & $<.001$ \\
\hline & Situation $(w)$ & -.12 & .01 & {$[-.13,-.10]$} & $<.001$ \\
\hline & Situation (b) & -.01 & .03 & {$[-.07, .05]$} & .826 \\
\hline & Situation $(w) \times$ Extraversion $(b)$ & -.02 & .01 & {$[-.03, .00]$} & .021 \\
\hline \multirow[t]{5}{*}{ Positivity vs. Negativity } & Intercept & 3.21 & .02 & {$[3.17,3.25]$} & $<.001$ \\
\hline & Extraversion (b) & .21 & .02 & {$[.16, .25]$} & $<.001$ \\
\hline & Situation (w) & .24 & .01 & {$[.22, .26]$} & $<.001$ \\
\hline & Situation (b) & .07 & .05 & {$[-.03, .17]$} & .199 \\
\hline & Situation $(w) \times$ Extraversion $(b)$ & .03 & .01 & {$[.01, .05]$} & .003 \\
\hline
\end{tabular}

Note: $N=394$. Model containing situational categories (Low-effort $=1$; High-effort $=0$ ): number of observations $=7,250$. Models containing situational dimensions: number of observations $=8,485$, scale 1 to 7 . All situations rated by observers based on ESM open-ended responses. $(\mathrm{w})$ = within-person. $(\mathrm{b})$ = between-person. Self-reported sociable behavior (DV, within-person), scale 1 to 5 . Extraversion $=$ standardized trait extraversion rated by self and informants. $b=$ unstandardized regression coefficient. SE $=$ standard error. 95\% CI = lower and upper bound of 95\% confidence interval.

(vs. high-effort), positive (vs. negative), or low-duty (vs. high-duty) situations had no significant effects on overall sociable behavior.

Within persons, all the situation categories and situation dimensions coded from participants' open-ended responses were significantly related to sociable behavior (low-effort vs. high-effort: $\gamma_{10}=.48, p<.001$; sociality: $\gamma_{10}=.30, p<.001$; duty: $\gamma_{10}=-.12, p<.001$; positivity vs. negativity: $\left.\gamma_{10}=.24, p<.001\right)$. Thus, being in a low-effort situation was associated with higher momentary sociable behavior than being in a high-effort situation. Similarly, situations with high scores in sociality and positivity vs. negativity and low scores in duty were associated with more sociable behavior.

For three of the models, the relationship between within-person situation and sociable behavior was moderated by extraversion (low-effort vs. high-effort: $\gamma_{11}=.08, p=.013$; duty $\gamma_{11}=-.02, p=.021$; positivity vs. negativity $\left.\gamma_{11}=.03, p=.003\right)$. See Figure $\mathbf{1}(\mathbf{A}, \mathbf{C}$, and $\mathbf{D})$ for the plotted cross-level interactions. This means that individuals high in extraversion who were in a situation with (for example) a high positivity vs. negativity score reported an additional boost in sociable behavior compared to individuals low in extraversion. There was no significant interaction effect for the sociality dimension of situations. To describe the personality-situation interaction we also performed simple slope tests, which revealed that the relation between situations and sociable behavior was stronger for participants with high scores on extraversion (one standard deviation above the mean; low-effort vs. high-effort: $b=.56, p<.001 ;$ duty: $b=-.13$, $p<.001$; positivity vs. negativity: $b=.27, p<.001)$, compared to participants with low values in extraversion (one standard deviation below the mean; low-effort vs. high-effort: $b=.39, p<.001 ;$ duty: $b=-.10, p<.001$; positivity vs. negativity: $b=.21, p<.001)$.

\section{Discussion}

Regarding the main effects of person and situation characteristics on sociable behavior, results were in line with our predictions and with those of previous studies (e.g., Fleeson \& Gallagher, 2009; Sherman et al., 2015). Extraversion significantly predicted average sociable behavior, with sociable behavior being assessed within 


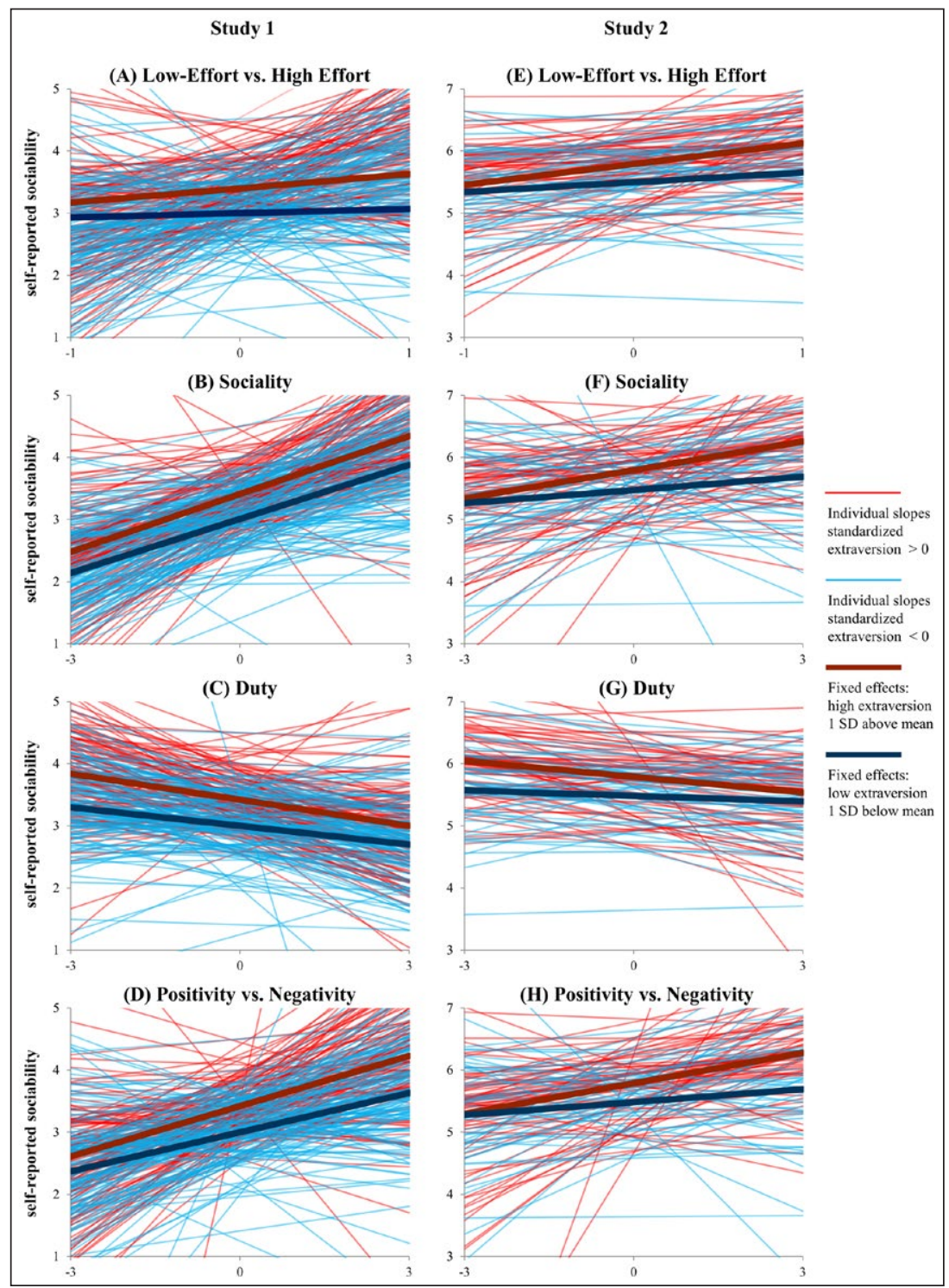

Figure 1: Interaction Effects Perspective 1.

Note: Interaction effects of situation (x axis) and actor extraversion (slopes) on self-reported sociable behavior.

social interactions and a strong measure of extraversion averaged across self- and informant-reports.

Within persons, specific situation characteristics were associated with self-reported sociable behavior. In addition to replicating previous findings (situational sociality as a predictor; Sherman et al., 2015), our results showed that self-reported sociable behavior is associated, within-person, with duty (negative), positive vs. negative, and low-effort vs. high-effort situations. This is in line with previous findings regarding task orientation (Fleeson, 2007) and the association with extraverted behavior and positive affect (e.g., Wilt et al., 2012). The results for between-person differences, however, were ambiguous: Only people who, on average, experienced more situations high on sociality reported higher sociable behavior. This confirms the findings by Sherman et al. (2015) who also reported a between-person effect of sociality situations on sociable behavior.

In contrast to previous studies, the current study provides initial evidence for person-situation interaction effects. The relationship between situation and sociable behavior was moderated by extraversion. Thus, extraverts acted especially sociable in situations with low-effort, positive, and low duty characteristics. There was, however, no interaction effect regarding the situational sociality dimension, which is in line with results reported by Sherman and colleagues (2015) and might suggest that it is not sociality per se, but other aspects of a situation that lead to a boost in sociable behavior for extraverts. To our knowledge, this is one of the first studies to find interaction effects when investigating behavior in reallife settings. Although the effect sizes were relatively small, they provide initial evidence for the existence of person-situation interaction effects on sociable behavior. In Study 2, we test whether these effects replicate in a study with a slightly different design, and also test additional questions about the role of social perspectives (e.g., partner-rated sociable behavior).

\section{Study 2}

Study 2 was based on the CONNECT dataset, a longitudinal study of personality and social relationships (Geukes, Breil et al., 2018; Geukes, Hutteman et al., 2018). In contrast to Study 1, an event-based experience 
sampling design was used. This allowed us to specifically investigate social interactions between partners, as behavioral and situational data were only collected when social interactions took place. Furthermore, all interaction partners were participants in the study, which made it possible to consider all perspectives of perceived sociable behavior.

Thus, Study 2 allowed us to test whether we could replicate the findings of Study 1 with a different sampling design. In addition, we were able to extend our understanding of different perspectives and partner effects by exploring the additional three perspectives. We expected that partners' perceptions of actors' sociable behavior are predicted by actors' extraversion (Perspective 2). Additionally, we explored whether perceiver effects (partner's perceptions of actor's behavior predicted by partner's extraversion; Perspective 3) and evoked behavior (actor's self-rated behavior predicted by partner's extraversion; Perspective 4) could be detected. Furthermore, possible situationextraversion and actor-partner extraversion interaction effects were explored for all four perspectives. In the following and the detailed documentation we are referring to, we report how we determined our sample size, all data exclusions, and all variables assessed as part of this project (cf. Simmons et al., 2012; see Geukes, Breil, et al., 2017 and osf.io/2pmcr for additional details regarding further procedures applied and other measures collected in CONNECT). Analyses from this dataset have been published elsewhere (Geukes, Nestler, Hutteman, Dufner et al., 2017; Geukes, Nestler, Hutteman, Küfner, \& Back, 2017; Human, Carlson, Geukes, Nestler, \& Back, in press; Humberg, Dufner, Schönbrodt, Geukes, Hutteman, Küfner et al., 2018; Humberg, Dufner, Schönbrodt, Geukes, Hutteman, van Zalk et al., 2018; Leckelt et al., 2018; Nestler, Geukes, \& Back, 2018; Nestler, Geukes, Hutteman, \& Back, 2017), but none of the presented results reported here overlap with any of the results in the published work.

\section{Method}

Participants. In October 2012, all psychology freshmen starting at the University of Münster, Germany, were invited to participate in the CONNECT study. Out of 140 individuals who registered as psychology students, 131 took part in the study. During the study, five participants dropped out, leaving a final sample of 126 participants. 124 (101 female) of those 126 participants completed all relevant measures for the present analyses (i.e., filled out the extraversion questionnaire and participated in the experience sampling). Age of participants ranged from 18 to $42(M=21.31, S D=3.95)$. Participants received course credit, monetary compensation (up to 260 Euro for providing all measures assessed in the CONNECT study), participation in a lottery for gift vouchers, and individual feedback on their personality and personality development. All procedures of this study were approved by the review boards of the University of Mainz and the University of Münster, and are in line with the recommendations of the DFG (German research foundation) and DGPs (German psychological society).
Procedures. Within the CONNECT study, participants first completed an online questionnaire containing measures of demographics and personality traits (including the Big Five). In addition to the self-rating, participants were asked to name (at least) two wellacquainted persons (e.g., family members or close friends) to provide informant-ratings of the same trait measures. In total, 244 informant-reports were submitted $\left(M_{n o}=2.97 ; S D_{n o}=0.57 ; 172\right.$ female; $M_{\text {age }}=28.51$; $S D_{\text {age }}=13.52$; range: $\left.15-63\right)$. Second, during the first three weeks of the semester and in two additional phases (one week near the middle and one week near the end of the semester; for a full timeline see codebook page 3 on osf.io/2pmcr), participants were asked to provide eventbased experience-sampling ratings using a smartphone survey (by Qualtrics). An iPod Touch was given to those students who did not own a smartphone. During those five weeks, participants were told to fill in the eventbased ratings after every social interaction with a fellow Psychology freshman who also participated in the study. A social interaction was defined as "an encounter with one or more people that lasts a least 5 minutes and in which one responds to the behavior of the other persons" (see Nezlek \& Leary, 2002; Nezlek, Schütz, Schröder-Abé, \& Smith, 2011; Reis \& Wheeler, 1991; Sekara, Stopczynski, \& Lehmann, 2016; Wheeler \& Nezlek, 1977 for similar procedures). Within the smartphone survey, participants had to select their respective interaction partner based on a list of surnames, pictures, and IDs.

The event-based ratings consisted of questions regarding the number of interaction partners, the situation, state affect as well as the ratings of their own and partner's behavior (for the full survey see codebook page 75-77 on osf.io/2pmcr). To receive full credit, participants were asked to report on at least 10 social interactions per week but were not restricted regarding the number of reports.

During the first semester a total of 8,004 social interactions were reported. Out of those social interactions, 1,293 were excluded because of unfinished entries, 14 due to missing situational information, and 125 because corresponding interaction partners did not provide extraversion ratings. A total of 6,572 social interactions remained, which resulted in an average of $53.87(S D=25.41, M d n=55$, range: $2-132$; days with interactions: $M=19.70, S D=7.47, M d n=20$, range: $2-38)^{7}$ social interactions per participant. As the interaction partners were also participants in this study, trait extraversion scores were matched with actors and partners for each social interaction. Because one social interaction could include the ratings of multiple actors, the total number of partner-reported actor behavior ratings was $10,893(M=89.29, S D=52.79, M d n=85)$.

\section{Measures}

Extraversion. Extraversion was measured with the three extraversion items of the 15 item Big Five Inventory-SOEP (BFI-S; Gerlitz \& Schupp, 2005). The items were answered on seven-point Likert scales ranging from 1 (does not apply at all) to 7 (applies perfectly). The agreement between selfratings and averaged informant-ratings for extraversion was $r=.56$. Cronbach's alpha was .86 for self-ratings and 
.80 for informant-ratings. An aggregated extraversion score was created by computing the mean of self- and mean informant-ratings.

Sociable Behavior. Sociable behavior was assessed via the smartphone survey and participants were asked to rate their own behavior as well as the behaviors of each interaction partner directly after social interactions. Sociable behavior was rated on a bipolar scale (Please judge your own behavior; please judge the behavior of her/him) from 1 (sociable) to 7 (withdrawn) and reversed for all subsequent analyses.

Situational assessments. In the experience-sampling questionnaire participants were asked to choose one out of 17 situation categories. Those categories were based on extensive pre-testing ${ }^{8}$ of typical situations for students (e.g., in class, studying, at lunch, partying). For a full overview of all situations and descriptive statistics see Table 2 .

Categorical situational codings. The situation categories were sorted into two broader categories: Low-effort (e.g., partying) and high-effort (e.g., studying) situations. Of these reports, $4,049(62 \%)^{9}$ were sorted into one of these categories (7,301 for interaction partner-reported actor behavior), the remaining reports could not be classified into either of these two categories.

Dimensional situational ratings. As in Study 1, the 17 situation categories were rated on all eight DIAMONDS dimensions by ten independent raters. Each category was rated on seven-point Likert scales ranging from 1 (does not apply at all) to 7 (applies perfectly) using the S8-II short version DIAMONDS questionnaire (Rauthmann \& Sherman, 2016b). The same variables as in Study 1 were selected for the main analyses (i.e., sociality, duty, and positivity vs. negativity; correlation between positivity and negativity of the averaged ratings: $r=-.87$ ).

Analytic strategy. Sociable behavior across perspectives was examined by calculating two different kinds of multilevel models. In the first model, we used the variable self-reported sociable behavior as the outcome variable to simultaneously test for Perspective 1 (i.e., Does my personality influence my behavior?) and Perspective 4 (i.e., Do other people's personalities influence my behavior?). To this end, a multilevel model similar to the model used in Study 1 was computed in which the self-reported sociable behavior of the actor was predicted by the respective situation variable, the extraversion of the actors and the situation $\times$ extraversion actor interaction. However, to test for perspective 4, we also included an extraversion score for the partner present in the situation. Because social interactions could include more than two people, the partner extraversion score was the mean of all involved partners' extraversion scores. Finally, we also included the partner extraversion $\times$ situation interaction. The estimated model was

$$
\begin{array}{cl}
\text { Level 1: } & y_{i j}=\beta_{0 j}+\beta_{1 j}(\text { sit })+\beta_{2 j}\left(e x t_{p a r t}\right)+ \\
& \beta_{3 j}\left(\text { sit } \times e x t_{p a r t}\right)+\varepsilon_{i j} \\
\text { Level 2: } & \beta_{0 j}=\gamma_{00}+\gamma_{01}\left(e x t_{a c t}\right)+\gamma_{02}\left(\text { sit }_{\text {mean }}\right)+ \\
& \gamma_{03}\left(e x t_{\text {part } \text { mean }}\right)+u_{0 j} \\
& \beta_{1 j}=\gamma_{10}+\gamma_{11}\left(e x t_{a c t}\right)+u_{1 j} \\
& \beta_{2 j}=\gamma_{20}+\gamma_{21}\left(e x t_{a c t}\right)+u_{2 j}
\end{array}
$$

Here, $y_{\mathrm{ij}}$ is the self-reported sociable behavior of the actor, sit is the respective situation variable, ext ${ }_{\text {part }}$ refers to the (mean) extraversion score of the partners present in the situation and ext $t_{\text {act }}$ is the extraversion score of the actor. From the perspective of the multilevel model, the partner extraversion score and the situation variable are level-1 predictors that may manifest themselves on the within-person and the between-person level. We therefore decided to person-center these two variables and to include the respective means, that is, sit mean $_{\text {and }}$ ant ${ }_{\text {part,mean' }}$, as level-2 predictors in the model. All level- 2 predictors were centered prior to estimating the model.

A second model was used to test the questions raised in Perspective 2 (Does my personality affect other people's perception of my behavior?) and Perspective 3 (Do other people's personalities influence their perception of my behavior?), the variable interaction partner-reported sociable actor behavior was used as a dependent variable. This resulted in an increase of 4,321 observations compared to the self-reported behaviors investigated in Perspective 1 and 4 (see above). As multiple partners could be present in one social interaction (who all judged the same actor) and given that in CONNECT all interactions refer to the same set of individuals (e.g., B and $C$ may be part of an interaction with person A but also person D), the second model is not a standard multilevel model but rather a cross-random effect model (see Baayen, Davidson, \& Bates, 2008; Judd, Westfall, \& Kenny, 2012; Nestler \& Back, 2017). This model includes a random effect, for the actors reflecting that some actors are judged as more sociable on average and random effects for the partners reflecting that some partners judge others as more sociable on average. The estimated model was

$$
\begin{aligned}
y_{i j l}= & \beta_{0 i j}+\beta_{1 j}(\text { sit })+\varepsilon_{i j l} \\
\beta_{0 j i}= & \gamma_{00}+\gamma_{01}\left(e x t_{a c t}\right)+\gamma_{02}\left(\text { sit }_{\text {mean }}\right)+\gamma_{03}\left(\text { ext }_{p a r t}\right)+ \\
& \gamma_{04}\left(e x t_{a c t} \times e x t_{p a r t}\right)+u_{0 i}+u_{0 j} \\
\beta_{1 j}= & \gamma_{10}+\gamma_{11}\left(e x t_{a c t}\right)+\gamma_{12}\left(e x t_{p a r t}\right)+u_{1 j}
\end{aligned}
$$

where $y_{\mathrm{ijl}}$ reflects partner's $j$ judgment of actor i's sociable behavior in situation $l$, and all other variable have the same interpretation as before. The situational variable was centered (within and between) around the partner. $^{10}$ Standardized actor and partner extraversion scores were added to the model. Furthermore, as done in previous models, the interactions between actor extraversion and situation (within), partner extraversion and situation (within), as well as actor extraversion and partner extraversion and their interaction were added as predictors:

\section{Results}

Table 6 presents the descriptive statistics, and intercorrelations for the examined variables. Multi-level analyses were applied using the R packages lme4 (Bates et al., 2018) and lmerTest (Kuznetsova et al., 2018; R version 3.4.3; see osf.io/w96mv for data and R-code). Results for the null models for self-reported and interaction partner-reported sociable actor behavior can be found 
Table 6: Means, Standard Deviations, and Intercorrelations of Sociable Behavior, Extraversion and Situational Variables (Study 2).

\begin{tabular}{|c|c|c|c|c|c|c|c|c|c|c|c|c|}
\hline & $N$ & $M$ & $S D$ & 2 & 3 & 4 & 5 & 6 & 7 & 8 & 9 & 10 \\
\hline 1 Self-reported Sociable Behavior (ESM) & 122 & 5.62 & 0.59 & .28 & .88 & .31 & .36 & .15 & .23 & .18 & -.21 & .24 \\
\hline 2 Partner-reported Sociable Behavior (ESM) & 124 & 5.76 & 0.36 & & .25 & .43 & .37 & .39 & .30 & .19 & -.22 & .29 \\
\hline 3 Mean perceived Sociable Behavior (ESM) & 122 & 5.77 & 0.57 & & & .25 & .28 & .14 & .24 & .18 & -.17 & .23 \\
\hline 4 Aggregated Extraversion & 124 & 5.25 & 0.91 & & & & .91 & .86 & .25 & .09 & -.22 & .26 \\
\hline 5 Self-reported Extraversion & 124 & 5.11 & 1.11 & & & & & .56 & .32 & .12 & -.25 & .29 \\
\hline 6 Informant-reported Extraversion & 120 & 5.39 & 0.94 & & & & & & .05 & -.01 & -.09 & .11 \\
\hline 7 Low-effort vs. High-effort (ESM-coded) & 121 & 0.55 & 0.20 & & & & & & & .79 & -.85 & .91 \\
\hline 8 Sociality (ESM-coded) & 122 & 5.96 & 0.25 & & & & & & & & -.88 & .90 \\
\hline 9 Duty (ESM-coded) & 122 & 3.60 & 0.50 & & & & & & & & & -.97 \\
\hline 10 Positivity vs. Negativity (ESM-coded) & 122 & 5.07 & 0.30 & & & & & & & & & \\
\hline
\end{tabular}

Note: ESM and ESM-coded variables were measured at level 1 (within-person, numbers of observations: 6,572 for self-reported sociable behavior; 10,893 for partner-reported sociable behavior; 6,572 for mean perceived sociable behavior; 4,049 for situational categories; 6,572 for situational dimensions). Extraversion variables were measured at level 2 (between-person). Self-reported sociable behavior and partner-reported sociable behavior do not necessarily refer to the same interactions. Mean perceived sociable behavior refers to the average perception of others' sociable behavior per interaction. Sociable behavior was reported on a 1 to 7 scale. Extraversion aggregate = mean of self-reported and mean informant-reported extraversion. Extraversion was reported on a 1 to 7 scale. Low-effort vs. High-effort categories were coded based on ESM categories as: 1 = Low-effort; 0 = High-effort. Sociality, duty, and positivity vs. negativity were coded based on ESM categories, on a 1 to 7 scale. All means, standard deviations, and correlations are at the between-person level. Significant correlations $(p<.05)$ in bold.

in Table 4. The ICCs (i.e., proportion of variance at the between-person level) were 33\% for self-reported sociable behavior and 34\% for interaction partner-reported sociable actor behavior. Results for the eight (2 dependent variables $\times 4$ situations) models can be found in Tables $\mathbf{7}$ and $\mathbf{8}$. Additional results for the random effects, the remaining DIAMONDS dimensions (Perspective 1), and separate self- and informant extraversion-ratings can be found in the online supplement (osf.io/w96mv). See Table 1 for a summary of predictions and results and Figures $\mathbf{1}$ and $\mathbf{2}$ for a graphic representation of selected results.

Perspective 1. Actor extraversion significantly predicted self-reported sociable behavior $\left(\gamma_{01}=.15, p=.005\right)$. That is, extraverts reported acting more sociable than introverts. The between-person situation differences did not significantly predict self-reported sociable behavior. This means, people who on average reported more situations with (for example) high scores in sociality or low scores in duty did not report more sociable behavior.

At the within-person level, all situational variables were significant predictors of self-reported sociable behavior (low-effort vs. high-effort: $\gamma_{10}=.25, p<.001$; sociality: $\gamma_{10}=.11, p<.001$; duty: $\gamma_{10}=-.06, p<.001$; positivity vs. negativity $\left.\gamma_{10}=.12, p<.001\right)$. Thus, being in a situation with (for example) low scores in duty was associated with higher sociability ratings.

For all models, the interactions between within-person situation and actor extraversion were significant predictors of self-reported sociable behavior. (low-effort vs. high-effort: $\gamma_{11}=.09, p=.014 ;$ sociality: $\gamma_{11}=.04, p=.031 ;$ duty: $\gamma_{11}=-.03$, $p=.003$; positivity vs. negativity: $\left.\gamma_{11}=.05, p=.007\right)$. That is, on average, the more positive and effortless a situation was, the more sociable participants described themselves to be, and these effects were stronger for participants higher in extraversion than those lower in extraversion. See Figure 1 $(\mathrm{E}, \mathrm{F}, \mathrm{G}, \mathrm{H})$ for cross-level interactions. Again, for descriptive purposes, we performed simples slope tests showing that the relation between situation categories/dimensions and self-reported sociable behavior was stronger for actors with high values in extraversion, (one standard deviation above the mean; low-effort vs. high-effort: $b=.33, p<.001$; sociality: $b=.15, p<.001 ;$ duty: $b=-.09, p<.001 ;$ positivity vs. negativity: $b=.16, p<.001)$ compared to actors with low values in extraversion (one standard deviation below the mean; low-effort vs. high-effort: $b=.16, p=.002$; sociality: $b=.07, p=.007 ;$ duty: $b=-.03, p=.021 ;$ positivity vs. negativity: $b=.07, p=.004$ ).

Perspective 2. Actor extraversion was a significant predictor of interaction partner-reported sociable actor behavior $\left(\gamma_{01}=.13 ; p<.001\right)$. Thus, an extravert (on average) was rated higher on sociable behavior by their interaction partners than an introvert. Among the situation variables, between persons, only low-effort vs. high-effort was a significant predictor of interaction partner-reported sociable actor behavior $\left(\gamma_{02}=.52, p=.047\right)$. That is, partners, who experienced more low-effort situations, also perceived (on average) more sociable behavior in others, but overall differences in experiencing other situations (i.e., sociality, duty, positivity vs. negativity) had no significant effects on interaction partner-reported sociable actor behavior.

All within-person situational variables predicted interaction partner-reported sociable actor behavior (loweffort vs. high-effort: $\gamma_{10}=.17, p<.001$; sociality: $\gamma_{10}=.10$, $p<.001 ;$ duty: $\gamma_{10}=-.04, p<.001 ;$ positivity vs. negativity: $\left.\gamma_{10}=.09, p<.001\right)$. This means, the perception of someone's 
Table 7: Fixed Effects for Multi-Level Models: Predicting Self-Reported Sociable Behavior by Extraversion, Situation, and Interaction Variables (Study 2; Perspective $1 \& 4$ ).

\begin{tabular}{|c|c|c|c|c|c|}
\hline Situation & Variable & $\boldsymbol{b}$ & SE & $95 \% \mathrm{CI}$ & $p$ \\
\hline \multirow{9}{*}{$\begin{array}{l}\text { Low-effort vs. } \\
\text { High-effort }\end{array}$} & Intercept & 5.65 & .05 & {$[5.55,5.74]$} & $<.001$ \\
\hline & Actor Extraversion (b) & .15 & .05 & {$[.05, .25]$} & .005 \\
\hline & Partner Extraversion (w) & .00 & .02 & {$[-.05, .05]$} & .952 \\
\hline & Partner Extraversion (b) & .06 & .12 & {$[-.18, .30]$} & .618 \\
\hline & Situation (w) & .25 & .03 & {$[.18, .31]$} & $<.001$ \\
\hline & Situation (b) & .50 & .28 & {$[-.01,1.05]$} & .077 \\
\hline & Situation $(w) \times$ Actor Extraversion (b) & .09 & .04 & {$[.02, .16]$} & .014 \\
\hline & Situation $(w) \times$ Partner Extraversion $(w)$ & .09 & .04 & {$[.01, .17]$} & .034 \\
\hline & Actor Extraversion (b) $\times$ Partner Extraversion (w) & .01 & .02 & {$[-.04, .06]$} & .734 \\
\hline \multirow[t]{9}{*}{ Sociality } & Intercept & 5.64 & .05 & {$[5.54,5.73]$} & $<.001$ \\
\hline & Actor Extraversion (b) & .16 & .05 & {$[.06, .26]$} & .002 \\
\hline & Partner Extraversion (w) & .00 & .02 & {$[-.04, .03]$} & .984 \\
\hline & Partner Extraversion (b) & .12 & .12 & {$[-.11, .34]$} & .315 \\
\hline & Situation (w) & .11 & .02 & {$[.08, .15]$} & $<.001$ \\
\hline & Situation (b) & .27 & .21 & {$[-.12, .68]$} & .186 \\
\hline & Situation $(w) \times$ Actor Extraversion (b) & .04 & .02 & {$[.00, .08]$} & .031 \\
\hline & Situation $(w) \times$ Partner Extraversion $(w)$ & .05 & .02 & {$[.01, .08]$} & .017 \\
\hline & Actor Extraversion (b) $\times$ Partner Extraversion (w) & .00 & .02 & {$[-.03, .04]$} & .789 \\
\hline \multirow[t]{9}{*}{ Duty } & Intercept & 5.64 & .05 & {$[5.54,5.73]$} & $<.001$ \\
\hline & Actor Extraversion (b) & .15 & .05 & {$[.06, .25]$} & .003 \\
\hline & Partner Extraversion (w) & .00 & .02 & {$[-.03, .04]$} & .901 \\
\hline & Partner Extraversion (b) & .10 & .12 & {$[-.13, .33]$} & .394 \\
\hline & Situation (w) & -.06 & .01 & {$[-.08,-04]$} & $<.001$ \\
\hline & Situation (b) & -.12 & .11 & {$[-.34, .09]$} & .268 \\
\hline & Situation $(w) \times$ Actor Extraversion (b) & -.03 & .01 & {$[-.05,-.01]$} & .003 \\
\hline & Situation $(w) \times$ Partner Extraversion $(w)$ & -.02 & .01 & {$[-.04, .00]$} & .069 \\
\hline & Actor Extraversion (b) $\times$ Partner Extraversion (w) & .01 & .02 & {$[-.03, .04]$} & .638 \\
\hline \multirow{9}{*}{$\begin{array}{l}\text { Positivity vs. } \\
\text { Negativity }\end{array}$} & Intercept & 5.64 & .05 & {$[5.54,5.73]$} & $<.001$ \\
\hline & Actor Extraversion (b) & .15 & .05 & {$[.05, .25]$} & .003 \\
\hline & Partner Extraversion (w) & .00 & .02 & {$[-.03, .04]$} & .952 \\
\hline & Partner Extraversion (b) & .09 & .12 & {$[-.15, .32]$} & .469 \\
\hline & Situation (w) & .12 & .02 & {$[.08, .15]$} & $<.001$ \\
\hline & Situation (b) & .24 & .19 & {$[-.13, .60]$} & .210 \\
\hline & Situation $(w) \times$ Actor Extraversion (b) & .05 & .02 & {$[.01, .08]$} & .007 \\
\hline & Situation $(w) \times$ Partner Extraversion $(w)$ & .04 & .02 & {$[.01, .08]$} & .023 \\
\hline & Actor Extraversion (b) $\times$ Partner Extraversion (w) & .01 & .02 & {$[-.03, .04]$} & .709 \\
\hline
\end{tabular}

Note: Model containing situational categories (Low-effort $=1$; High-effort $=0$ ): $N=121$, number of observations $=4,049$. Models containing situational dimensions: $N=122$, number of observations $=6,572$, scale 1 to 7 . All situational dimensions rated by observers based on ESM categories. $(\mathrm{w})$ = within-person. $(\mathrm{b})$ = between-person. Self-reported sociable behavior (DV, within-person), scale 1 to 7 . Actor extraversion = standardized trait extraversion rated by self and informants. Partner extraversion $=$ mean extraversion of involved interaction partners for each interaction, rated by self and informants. $b=$ unstandardized regression coefficient. $\mathrm{SE}=$ standard error. 95\% $\mathrm{CI}=$ lower and upper bound of 95\% confidence interval. 
Table 8: Fixed Effects for Multi-Level Models of Interest: Predicting Interaction Partner-Reported Sociable Actor Behavior by Extraversion, Situation, and Interaction Variables (Study 2; Perspective 2 \& 3).

\begin{tabular}{|c|c|c|c|c|c|}
\hline Situation & Variable & $\boldsymbol{b}$ & SE & $95 \% \mathrm{CI}$ & $p$ \\
\hline \multirow{8}{*}{$\begin{array}{l}\text { Low-effort vs. } \\
\text { High-effort }\end{array}$} & Intercept & 5.71 & .06 & {$[5.60,5.82]$} & $<.001$ \\
\hline & Actor Extraversion (b) & .13 & .03 & {$[.08, .19]$} & $<.001$ \\
\hline & Partner Extraversion (b) & .07 & .05 & {$[-.03, .18]$} & .156 \\
\hline & Situation $(w)$ & .17 & .03 & {$[.10, .23]$} & $<.001$ \\
\hline & Situation (b) & .52 & .26 & {$[.01,1.02]$} & .047 \\
\hline & Situation $(w) \times$ Actor Extraversion (b) & .07 & .03 & {$[.02, .12]$} & .003 \\
\hline & Situation $(\mathrm{w}) \times$ Partner Extraversion $(\mathrm{b})$ & .03 & .04 & {$[-.03, .10]$} & .330 \\
\hline & Actor Extraversion $(b) \times$ Partner Extraversion $(b)$ & .06 & .01 & {$[.03, .09]$} & $<.001$ \\
\hline \multirow[t]{8}{*}{ Sociality } & Intercept & 5.72 & .05 & {$[5.62,5.83]$} & $<.001$ \\
\hline & Actor Extraversion (b) & .13 & .02 & {$[.08, .18]$} & $<.001$ \\
\hline & Partner Extraversion (b) & .10 & .05 & {$[.01, .20]$} & .041 \\
\hline & Situation $(w)$ & .10 & .02 & {$[.07, .13]$} & $<.001$ \\
\hline & Situation (b) & .23 & .19 & {$[-.14, .60]$} & .231 \\
\hline & Situation $(w) \times$ Actor Extraversion $(b)$ & .02 & .01 & {$[-.01, .04]$} & .151 \\
\hline & Situation $(\mathrm{w}) \times$ Partner Extraversion $(\mathrm{b})$ & .01 & .02 & {$[-.02, .04]$} & .556 \\
\hline & Actor Extraversion $(b) \times$ Partner Extraversion (b) & .05 & .01 & {$[.03, .07]$} & $<.001$ \\
\hline \multirow[t]{8}{*}{ Duty } & Intercept & 5.72 & .05 & {$[5.62,5.82]$} & $<.001$ \\
\hline & Actor Extraversion (b) & .13 & .02 & {$[.08, .18]$} & $<.001$ \\
\hline & Partner Extraversion (b) & .10 & .05 & {$[.00, .20]$} & .050 \\
\hline & Situation (w) & -.04 & .01 & {$[-.06,-.02]$} & $<.001$ \\
\hline & Situation (b) & -.07 & .10 & {$[-.26, .12]$} & .474 \\
\hline & Situation $(w) \times$ Actor Extraversion (b) & -.02 & .01 & {$[-.03,-.01]$} & .003 \\
\hline & Situation $(\mathrm{w}) \times$ Partner Extraversion $(\mathrm{b})$ & -.01 & .01 & {$[-.03, .00]$} & .109 \\
\hline & Actor Extraversion $(b) \times$ Partner Extraversion $(b)$ & .05 & .01 & {$[.03, .07]$} & $<.001$ \\
\hline \multirow{8}{*}{$\begin{array}{l}\text { Positivity vs. } \\
\text { Negativity }\end{array}$} & Intercept & 5.72 & .05 & {$[5.62,5.82]$} & $<.001$ \\
\hline & Actor Extraversion (b) & .13 & .02 & {$[.08, .18]$} & $<.001$ \\
\hline & Partner Extraversion (b) & .09 & .05 & {$[-.01, .19]$} & .067 \\
\hline & Situation (w) & .09 & .02 & {$[.06, .12]$} & $<.001$ \\
\hline & Situation (b) & .18 & .17 & {$[-.14, .50]$} & .279 \\
\hline & Situation $(w) \times$ Actor Extraversion (b) & .03 & .01 & {$[.01, .05]$} & .008 \\
\hline & Situation $(\mathrm{w}) \times$ Partner Extraversion $(\mathrm{b})$ & .02 & .02 & {$[-.01, .05]$} & .191 \\
\hline & Actor Extraversion $(\mathrm{b}) \times$ Partner Extraversion $(\mathrm{b})$ & .05 & .01 & {$[.03, .07]$} & $<.001$ \\
\hline
\end{tabular}

Note: Model containing situational categories (Low-effort $=1$; High-effort $=0$ ): $N=124$ (actor), 121 (partner), number of observations $=7,301$. Models containing situational dimensions: $N=124$ (actor), 122 (partner), number of observations $=10,893$, scale 1 to 7 . All situational dimensions rated by observers based on ESM categories. $(w)=$ within-person. (b) = between-person. Interaction partner-reported sociable actor behavior (DV, within-person), scale 1 to 7 . Actor extraversion = standardized trait extraversion rated by self and informants. Partner extraversion $=$ Standardized trait extraversion rated by self and informants. Situations (within \& between) were centered around partner. $b=$ unstandardized regression coefficient. SE $=$ standard error. 95\% $\mathrm{CI}=$ lower and upper bound of 95\% confidence interval.

behavior was predicted not only by her extraversion, but also the situation she was in.

For three of the four models, the interaction between within-person situation and actor extraversion was significant (low-effort vs. high-effort: $\gamma_{11}=.07$, $p=.003$; duty: $\gamma_{11}=-.02, p=.003$; positivity vs. negativity: $\left.\gamma_{11}=.03, p=.008\right)$. See Figure $2(\mathbf{A}, \mathbf{C}$, and $\mathbf{D})$ for crosslevel interactions. That is, extraverts were perceived as 


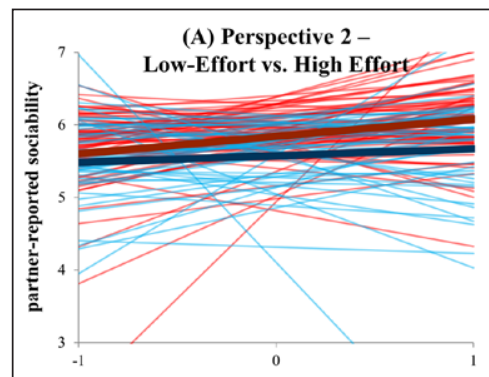

(B) Perspective 2 - Sociality

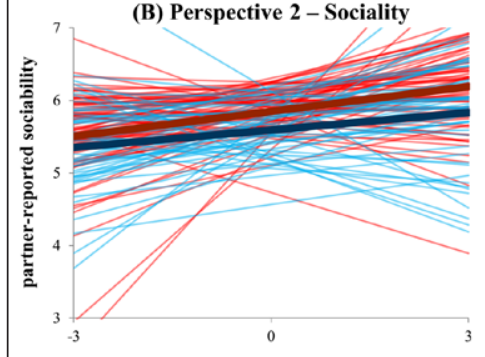

(C) Perspective 2 - Duty
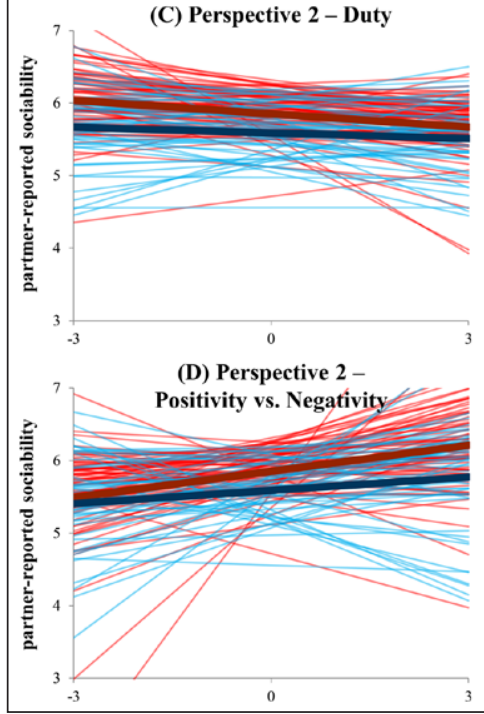

(E) Perspective 3 - Actor Extraversion

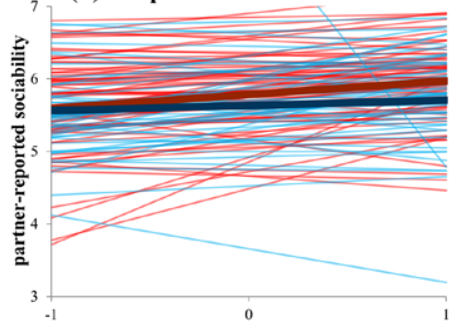

(F) Perspective 4 -

Low-Effort vs. High Effort

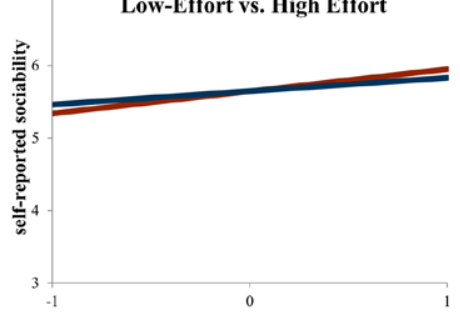

(G) Perspective 4-Sociality

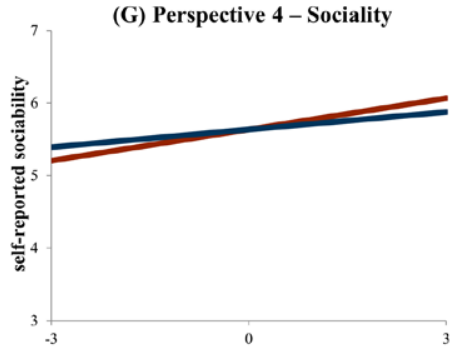

Individual slopes standardized
extraversion $<0$

Fixed effects high extraversio

Fixed effects: Pixed efrects: 1 SD below mean

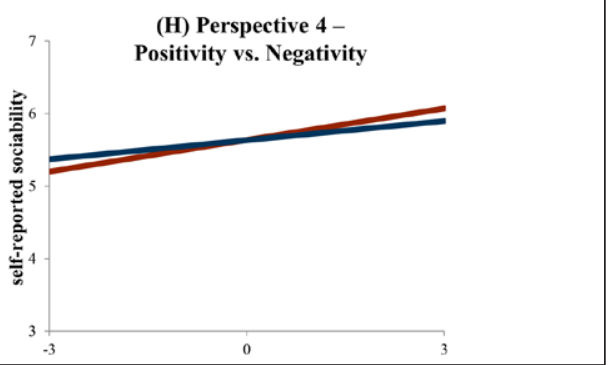

Figure 2: Interaction effects perspective 2, 3, and 4.

Note: A-D: Interaction effects of situation (x-axis) and actor extraversion (slopes) on partner-reported sociable actor behavior. E: Interaction effect of actor extraversion (x-axis) and partner extraversion (slopes) on partner-reported sociable actor behavior. $\mathrm{F}-\mathrm{H}$ : Interaction effects of situation (x-axis) and partner extraversion (slopes) on self-reported sociable behavior. As partner interaction was included at Level 1 there are no individual slopes for F, G, and H.

especially sociable in specific situations (i.e., low-effort categories, low duty situations, high positivityvs. negativity situations). There was no significant interaction for the sociality dimension. Simple slope tests revealed that the relation between situation characteristics and interaction partner-reported sociable actor behavior was stronger for actors with extraversion values of one standard deviation above the mean (low-effort vs. high-effort: $b=.24, p<.001$; duty: $b=-.06, p<.001 ;$ positivity vs. negativity: $b=.12$, $p<.001)$ compared to actors with extraversion values of one standard deviation below the mean (low-effort vs. high-effort: $b=.09, p=.037$; duty: $b=-.03, p=.013$; positivity vs. negativity: $b=.06, p=.002$ ).

Perspective 3. For three of the four models (including low-effort vs. high-effort, duty, and positivity vs. negativity as situation variables) partner extraversion was not significantly related to interaction partner-reported sociable actor behavior. However, there was a significant effect in the model including sociality as a situational dimension $\left(\gamma_{03}=.10, p=.041\right)$. This means that an extraverted perceiver did not necessarily perceive others as acting more or less sociable. Main effects of situation variables on interaction partner-reported sociable actor behavior are described in Perspective 2 above.

At the within-person level the interactions between situation (within) and partner extraversion were also not significant. However, there was a significant interaction between actor extraversion and partner extraversion on interaction partner-reported sociable actor behavior $\left(\gamma_{04}=.06, p<.001\right.$; see Figure 2E). Thus, if both actor and partner were extraverts, actor behavior was perceived as especially sociable. A simple slope test showed that the relation between actor extraversion and interaction partner-reported sociable actor behavior was stronger for partners with extraversion scores of one standard deviation above the mean $(b=.19, p<.001)$ compared to partners with extraversion of one standard deviation below the mean $(b=.07, p=.021)$.

Perspective 4. Partner extraversion did not significantly predict self-reported sociable behavior, neither between 
nor within persons. That is, extraverted partners did not evoke more self-perceived sociable behavior in actors. Main effects of situation variables on self-reported sociable behavior are described in Perspective 1 above.

At the within-person level, the situational categories and the DIAMONDS dimensions, sociality and positivity vs. negativity (within) interacted with partner extraversion (within) to significantly predict self-reported sociable behavior (low-effort vs. high-effort: $\beta_{3 j}=.09, p=.034$; sociality: $\beta_{3 j}=.05, p=.017$; positivity vs. negativity: $\beta_{3 j}=.04, p=.023$; see Figure 2F, G, H ). That is, participants reported a boost in sociable behavior in situations with low-effort, sociality, and positivity, and this effect was stronger when participants were with extraverted partners. Additional simple slope tests showed that the relation between those situation characteristics and self-reported sociable behavior was stronger for social interactions with high values in partner extraversion (one standard deviation above the mean; low-effort vs. high-effort: $b=.30, p<.001$; sociality: $b=.14, p<.001$; positivity vs. negativity: $b=.14$, $p<.001)$ compared to social interactions with low values in partner extraversion (within, one standard deviation below the mean; low-effort vs. high-effort: $b=.19, p<.001$; sociality: $b=.08, p<.001$; positivity vs. negativity: $b=.09, p$ $<.001)$. Furthermore, the interaction of actor extraversion and partner extraversion was not a significant predictor of self-reported sociable behavior.

\section{Discussion}

The purpose of Study 2 was to replicate findings from Study 1 in a different sample with an event-based instead of a time based experience sampling and to examine different social perspectives on sociable behavior. Overall, the results of Study 2 mostly replicate the findings of Study 1. The ICC for sociable behavior (i.e., proportion of variance at the between-person level) was higher than in Study 1 and comparable to previous studies (Fleeson \& Gallagher, 2009; Sherman et al., 2015). Self-reported sociable behavior was again predicted by trait extraversion. The situational variables low-effort situations, sociality, duty and positivity vs. negativity all predicted sociable behavior. As in Study 1, interaction effects were found across different situational dimensions and categories. According to these findings, extraverts reported a stronger boost in sociable behavior compared to introverts when in low-effort, social, low duty, and positive situations.

We also tested additional research questions linked to Perspectives 2 through 4 , which we could not test in Study 1. Results for Perspective 2 support the hypothesis that interaction partner-reported sociable actor behavior is associated with actor extraversion, meaning that extraversion predicts not only self-reported but also otherreported behavior. This replicated previous results from laboratory studies (e.g., Back et al., 2009; Borkenau et al., 2004; Eaton \& Funder, 2003) in a field setting. In line with the results of self-reported behavior, there were situationextraversion interaction effects on interaction partnerreported actor behavior. Thus, extraverts self-reported a boost of sociable behavior in specific situations and this was reflected in observations by interaction partners (except for the sociality dimension).
Although therewasasizableamount ofvariation between perceivers, extraverted perceivers generally did not rate others as especially sociable (we did find this effect in only one of the four models). Again, this replicates laboratory findings from Eaton and Funder (2003) in a field setting. There was, however, an interaction between actor's and partner's extraversion for predicting interaction partnerreported sociable actor behavior, but not self-perceived sociable behavior. This means, if Andy and Patsy are both extraverts, Patsy perceives Andy as especially sociable, but it does not predict Andy's self-perception of his sociable behavior. This might suggest that there may be perceiver effects, but only for specific (extraverted) actors.

The results for evoked behavior (Perspective 4) show that partner extraversion did not predict self-reported behavior (neither within nor between persons). However, there were significant interaction effects between partner extraversion and situation (low-effort vs. high-effort, sociality and positivity vs. negativity). Hence, in general Andy is not influenced by his partner's extraversion, but in specific low-effort/positive/social situations he acts especially sociable when around extraverts, while in higheffort/negative/non-social situations he acts less sociable around extraverts than introverts.

\section{General Discussion}

The aim of this research was to investigate predictors of sociable behavior during real-life social interactions using data from two experience-sampling studies. Compared to previous research, we provided a number of extensions that allowed for a more comprehensive examination of these relationships. First, trait extraversion was assessed by both self- and informant-reports. ${ }^{11}$ This enabled us to analyze personality and person-situation interaction effects based on a more comprehensive and less methoddependent assessment of extraversion. Second, more objective situational categories as well as observer-rated situational dimensions were included. This allowed us to examine situation and person-situation effects on sociable behavior across both kinds of approaches to the assessment of situations that are currently discussed. Third, we focused on situational dimensions and categories as well as their interplay with trait extraversion within naturally-occurring social interactions that took place outside the lab. Fourth, analyses were replicated across cultures (US-American and German) and respective research teams as well as across time- and event-based approaches. Results underline the importance of both personality and situation main effects that were found in previous research using different methodologies. In addition, we found consistent evidence for person-situation interaction effects. For all three kinds of effects, differentiated patterns of results were revealed across social perspectives. Of course, anytime exploratory analyses are conducted on a large number of variables, we should be wary of over-interpreting differences in patterns of results. The replication of the analyses for Perspective 1 across two different datasets and the relatively consistent pattern of results across situational measures somewhat mitigate these concerns, but for Perspectives 2 through 4 , our conclusions must necessarily be more tentative because these perspectives were only examined in one 
study. All of these results raise interesting opportunities for future studies on which to follow up.

\section{Main Effects of Extraversion and Situations on Sociable Behavior}

As expected, extraversion was related to sociable behavior. This empirical association is in line with conceptualizations of extraversion that include sociability as a key facet of this trait (e.g., DeYoung, Quilty, \& Peterson, 2007; John \& Srivastava, 1999). It also replicates findings from previous laboratory and field studies regarding sociable/extraverted behavior (e.g., Back et al., 2009; Borkenau et al., 2004; Ching et al., 2014; Eaton \& Funder, 2003; Fleeson \& Gallagher, 2009; Judge et al., 2014; Sherman et al., 2015). By including an aggregate of self- and informant-reported extraversion and focusing on interaction partner-reported actor behavior (in addition to self-reported behavior) we were able to provide relatively robust and method-independent evidence for the relation between extraversion and sociable behavior.

Similar to the results of Eaton and Funder (2003), we did not find much evidence for perceiver or evoked behavior main effects in relation to extraversion and sociable behavior. For perceiver effects, this corresponds with findings regarding the similarity between self-rated traits and the perception of others' traits, for which typically no effects for extraversion are found (e.g., Beer \& Watson, 2008; Wood, Harms, \& Vazire, 2010). Regarding evoked behavior, laboratory research suggests that it is not sociability per se, but more specific behaviors (e.g., engages in constant eye contact with partner, cf. Eaton $\&$ Funder, 2003) that tend to be evoked depending on partner's extraversion.

For both self-reported and interaction partner-reported sociable actor behavior, there were strong effects for within-person situational variables. Thus, even in the circumscribed broader context of social interactions, people varied in their sociable behavior based on situational categories or dimensions. In other words, people acted more sociable in social interactions that provided positive cues (e.g., celebrating a party) compared to social interactions that provided task-oriented cues (e.g., having a study group meeting). In contrast to Sherman and colleagues (2015), situation selection (i.e., betweenperson differences in situation) effects were ambiguous, which might be explained by the fact that we excluded situations in which no social interaction took place (i.e., between-person differences did not include the choice whether to be in social interaction or not).

Overall, the results underline the importance of both situation and personality main effects when predicting behavior. This is consistent with previous empirical research (e.g., Fleeson, 2007; Sherman et al., 2015) and an integrative theoretical focus on person and situation effects (e.g., Fleeson \& Noftle, 2009; Funder, 2009). Considering different person-situation theories, the results support WTT (Fleeson \& Jayawickreme, 2015): Extraverted individuals, on average, acted more sociable, but individuals had a wide distribution of states, which can be explained by situational variables. The withinperson differences for situations are also in line with situation-based behavioral contingencies as postulated in the CAPS (Michel \& Shoda, 1995) model.

\section{Person-Situation Interaction Effects on Sociable Behavior}

In contrast to previous research that simultaneously investigated the influence of personality and situation on sociable/extraverted behavior (e.g., Ching et al., 2014; Sherman et al., 2015), we found person-situation interaction effects in both studies. This holds for selfand interaction partner-reported sociable actor behavior and was consistent across most of the tested situational variables. Specifically, extraverts acted particularly sociable in situations characterized by low-effort, positivity (i.e., low negativity), and a lack of duty.

By extending our analyses to further social perspectives two additional kinds of interaction effects were revealed; perceiver effects (actor extraversion x partner extraversion effects on interaction partner-reported sociable actor behavior) and evoked behavior (partner extraversion $x$ situation effects on self-reported sociable behavior). With regard to the former, extraverted participants perceived more sociable behavior, but only in their extraverted interaction partners. Regarding the latter, participants self-reported more sociable behavior when interacting with extraverts in positive social situations but less sociable behavior when interacting with an extravert in negative non-social situations. That is, extraverts tended to evoke self-reported sociable behaviors but only in situations that activate the trait of extraversion. In situations that do not activate the trait of extraversion, results suggest some sort of a contrast effect when around extraverts. These exploratory results show that personsituation interactions in real-life contexts can be complex and require the consideration of actor and partner personality traits, behavioral self- and other-reports of both interaction partners, and of situational features.

Comparing our study with previous research, there are three main differences that might explain the emergence of person-situation interaction effects. First, we only included situations in which social interaction took place, thus focusing on a specific context within participants' real life. Situational features (e.g., positivity, loweffort, duty) might only activate trait differences (e.g., extraversion differences), leading to observable individual differences (e.g., differences in sociable behavior), if embedded in a context in which they are relevant (e.g., real-life social interactions). Second, we included traitrelevant situational variables that are theoretically connected with sociable behavior (i.e., positivity, duty, effort). Third, those situational variables were based on observer-rated situational dimensions and more objective situational categories. Because of an expected correlation between situation perception and behavior as well as personality, a sole focus on subjective self-reported situations would have most likely underestimated personsituation interaction effects.

These explanations are in line with TraitActivation Theory (Tett \& Guterman, 2000), which specifies that individual differences in extraversion should be particularly salient in situations that activate extraversion-related behavior 
and/or contain extraversion-relevant situational cues. In fact, other studies that support Trait Activation Theory have also found interaction effects only in very specific settings (e.g., workplace settings; Lievens et al., 2006; Tett \& Burnett, 2003) and have relied on an objective situational categorization (e.g., Tett \& Guterman, 2000). Of course, it is important to directly test these proposed moderators, as it is also possible that the inconsistency in findings across the literature reflects normal variation due to sampling error, and may suggest that person-situation interactions tend to be small and difficult to detect.

Following the CAPS model (Mischel \& Shoda, 1995), our results can be interpreted as the effect of individual differences in if-then patterns: If people are in social interactions with specific situational features (e.g., positivity), they will show sociable behavior. These if-then patterns can be moderated by individual dispositions (i.e., high trait extraversion). Those interaction effects can also be incorporated into WTT, which focuses on both main effects but does not exclude interaction effects which could influence the distribution of states. In summary, our findings are consistent with a range of theories regarding person-situation transactions, and emphasize the importance of simultaneously examining person and situation effects as well as their potential interactions.

It should also be noted, however, that compared to the main effects, the interaction effects were of relatively small size. Also, more research is needed to replicate the present findings across social perspectives. In doing so, future research should try to explain why there are perceiver effects only for a specific constellation of actors and partners and why extraverted partners evoke more sociable behavior in some and less sociable behavior in other situations.

\section{Limitations and Future Directions}

A number of limitations of the present research should be noted that point to further important ways to extend the real-life investigation of personality and interpersonal behavior. First of all, in both studies the samples were limited to college students. On the one hand, this made it easier to compare results across studies. On the other hand, there might be less between-person variance as these samples involve relatively restricted variation (cf. Noftle \& Fleeson, 2010). Future research needs to examine whether these findings generalize to other populations and settings (e.g., social interactions in work-related contexts, social interactions in family contexts).

Second, future research might extend the assessment of behavior. Here, we focused on self- and partnerreported real-life behavior within the context of social interactions and used both a time- and an event-based approach. In Study 1, participants reported on onehour time intervals, which presumably resulted in a report of the average behavior across this time interval. Thus, we do not know how much time was actually spent in social interactions within that hour. In Study 2, this was not an issue due to the event-based sampling. However, behavior was only reported when interacting with fellow psychology first-year students and not with other interaction partners, potentially limiting variance in behavior. One particularly promising addition would be the application of the emerging social sensing assessment techniques that allow for large-scale assessments of objective behavioral indicators within individuals' daily lives (see Harari et al, 2016; Miller, 2012; Schmid-Mast, Gatica-Perez, Frauendorfer, Nguyen, \& Choudhury, 2015; Wrzus \& Mehl, 2015, for overviews).

Third, future research might extend the ways in which situational features are assessed in real-life. Based on Rauthmann and colleagues' (2015) suggestions for ideal real-life situational research, we considered a number of relevant criteria (multiple people, multiple situations, multiple observations, different groups). In addition, we chose to add more objective situational categories (low-effort vs. high-effort) as well as observer-rated situational dimensions (DIAMONDS), integrating different approaches to the conceptualization and assessment of situations. Nevertheless, the initial categorization of situational features was based on self-reports and, especially the open responses used in Study 1, may have already contained filtering through the lens of the participants' views (cf. Sherman et al., 2015). Thus it could be possible that extraverted participants described their situations in more sociable ways, thereby biasing the ESM codings. While mean ESM situation ratings (Study 1) were not related to extraversion scores of participants, future research should still address this limitation and assess situational characteristics based on observer descriptions or objective assessments. Again, novel mobile sensing techniques such as the Electronically Activated Recorder (Mehl et al., 2001) or the narrative clip (http://getnarrative. com) are promising tools for the objective assessment of situational features in real-life contexts (e.g., Wrzus $\&$ Mehl, 2015). Independent of the kind of assessment technique, future research might also extend the kind of situational features assessed. Within the context of social interactions, we focused on positive, low effort, low duty activities and results suggest that these dimensions accentuated the differences in sociable behavior between extraverts and introverts. A closer investigation of those situations, thus extracting relevant situational cues in a narrower fashion (e.g., friendliness of interaction partner; discussion topic), would be an interesting addition.

Fourth, another relevant task for future research is to provide more empirical evidence for specific person and situation effects across social perspectives. Study 2 was the first real-life study to include all four perspectives on the determinants of sociable behavior; thus, our results offer a first glimpse at possible effects. However, results need to be replicated in future studies. In this respect it would be fruitful to broaden the sample and include other interaction partners (e.g., hometown friends, parents) and investigate all perspectives. For example, it could be possible that evoked behavior (i.e., the influence of partners' extraversion) is only shown when interacting with parents but not with peers or teachers. Those perspectives could also be expanded by adding metaperceptions (e.g., Is Andy's sociable behavior influenced by how Andy perceives Patsy's perception of Andy's 
behavior?; cf. Schaffhuser et al., 2014). Furthermore, social relationships between interaction partners, for example liking/friendship (e.g., Ackerman \& Corretti, 2015; Ilmarinen, Vainikainen, Verkasalo, \& Lönnqvist, 2015; Wilson et al., 2015) or attraction/romantic relationships (e.g., Asendorpf, Penke, \& Back, 2011; Vater \& SchröderAbé, 2015), might also influence or moderate the effects. For example, one could imagine that attraction leads to sociable behavior for some people, while for others it results in reserved behavior.

Fifth and finally, the present approach can be extended to broader and other behavioral domains. For the present investigation, we decided to solely focus on a one-item sociable behavior measure, which made it possible to give a comprehensive and specific overview of one important behavior, which is connected to crucial outcomes such as life satisfaction and happiness (e.g., Emmons \& Diener, 1986). However, from a psychometric perspective it might be fruitful to measure sociable behavior with multiple items. Furthermore, there are several implications for behavioral research in general. The focus on a broad but circumscribed situational context (i.e., social interaction) in which effects of more specific situational dimensions and categories are examined seemed beneficial and can be translated to the investigation of other behaviors. For example, conscientious behavior (e.g., Jackson et al., 2010) could be investigated in a context related to work and study. Within this context, situational dimensions (e.g., stress) and categories (e.g., bosssubordinate interaction) can be analyzed as predictors of behavior. Furthermore, studying different social perspectives on behavior would be a valuable addition for a variety of behavioral domains. For example, agreeable partners might evoke communal behavior in certain situations but not in others (e.g., Graziano, Habashi, Sheese, \& Tobin, 2007). Correspondingly, conducting more multi-methodological real-life studies will help us to further expand our knowledge of the determinants and interplay of everyday behaviors.

\section{Conclusion}

Sociable behavior is connected to a variety of relevant social outcomes. The present research adds to and expands previous knowledge about predictors of sociable behavior in real-life. First, independent influences from personality and situation on sociable behavior were replicated across time-based and event-based longitudinal methodologies. Second, we provided evidence for small but consistent person-situation interaction effects on sociable behavior. Third, by including trait ratings and behavioral perceptions from interaction partners, we provided a more comprehensive and nuanced understanding of how sociable behavior is shaped in reallife social interactions. Future research studying behavior in relevant contexts with rich, real-life, multi-methodological data will help to replicate and broaden our understanding of the complex pattern of when and why some people act sociable and others do not.

\section{Data Accessibility Statement}

On our OSF page (osf.io/w96mv), we publish all data necessary to reproduce reported results and provide scripts for all data analyses reported in this manuscript.

\section{Notes}

1 Please note, that we use interaction with two different meanings: (1) social interaction, (2) statistical personby-situation interaction. In all instances in which we refer to the former, we ensured that it is accompanied by "social" (i.e., social interaction) or "partner" (i.e., interaction partner) as its attributes to keep it distinct from the statistical term "interaction".

${ }^{2}$ A Multilevel Analyses regarding the number of observations per day (nested within persons) revealed a between-person variance of 0.23 and a within person variance of 0.82 for Study 1 .

${ }^{3}$ We are aware that this categorization is only one of many possible options of comparing situational categories. During initial exploratory analyses we also tested different approaches such as active participation vs. social responsibility (excluding the social entertainment category; cf. Watson, 1992). Results were mostly similar for all approaches, but we ultimately decided for the categorization in low-effort vs. high-effort situations because this was the broadest approach and included most observations. For results please refer to our R-code on osf.io/w96mv.

${ }^{4}$ Please note that more specifically, observations were nested within days within persons. Therefore, we additionally calculated all models with a three-level structure. As results did not differ, we report the more parsimonious two-level models throughout the paper. The same applies to all results in Study 2. For results regarding the three-level models please refer to our R-code on osf.io/w96mv.

${ }^{5}$ For ease of interpretation and due to the high correlations among DIAMONDS scores, as well as the high number of possible predictors, a different model was calculated for each situational dimension. We are aware, that in this case these dimensions do not represent completely distinct constructs, but rather serve as alternative ways of demonstrating similar situational influences that drive sociable behavior.

${ }^{6}$ In the text, results for (actor) extraversion as a predictor are reported for the model including situational categories (low-effort vs. high-effort) only. Results for the other models are similar and can be found in the corresponding tables (Tables 4, 6, and 7).

${ }^{7}$ A Multilevel Analyses regarding the number of observations per day (nested within persons) revealed a between-person variance of 0.30 and a within person variance of 2.62 for Study 2 .

8 The pilot-testing of the situation assessment was based on the investigation of 20 psychology students at the University of Münster where the CONNECT study took place. For one week, participants of the pilot study had to report on every social interaction with fellow students or with peers of the same age. After each interaction, participants wrote down the situational activity (open response item, e.g., studying, playing soccer, eating) and the place where the interaction happened (e.g., at University, on the soccer field, in the kitchen of the shared flat). They were asked to include interactions via SMS, Email, or phone. Subsequently, these open answers 
(20 persons, 7 days) were clustered into categories based on a qualitative extraction, the 17 most frequent ones were used in the CONNECT study. For further details see the Connect Codebook at osf.io/2pmcr, event-based assessment, p. 22 and pp. 75-77.

${ }^{9}$ We realize that this is a relatively low percentage (compared to $82 \%$ in Study 1), which is mostly due to the fact that we did not include the situation category: "university: outside class" (1564 observations) to neither the low-effort nor high-effort categorization. However, we believe that the advantages of having two rather objective and distinct categories outweighs the lower power due to a lower number of observations. Furthermore, considering the results, even with this lower number we find consistent effects of personality, situation, and personality $x$ situation interaction effects.

${ }^{10}$ Centering around the partner for this model was decided before analyses and done for better comparison with previous models as the situation is centered around the person who provided the situational and behavioral rating. This was the actor for Perspective 1 and 4 and the partner for Perspective 2 and 3, respectively. Centering the situation around the actor for Perspective 2 and 3 did not significantly change the results for most parts. Partner extraversion however, was significantly related to interaction partner-reported sociable actor behavior in three of the four models. This is most likely due to the fact that when centering around the actor, one does not control for partners'/perceivers' situational experiences (i.e., extraverts are in more situations associated with extraversion and therefore perceive others as more sociable). In fact, when additionally entering mean perceiver/partner situational experience (situation between) to the models, effect sizes for partner extraversion were similar to the original results. For results please refer to our R-code on osf.io/w96mv.

${ }^{11}$ When separately investigating self-reported and informant-reported extraversion (see osf.io/w96mv, Additional Tables, S3, S7, S8), results were, for the most part, consistent with the aggregated extraversion score. There were a few differences, however: In Study 1 the duty $\times$ self-reported extraversion interaction was not significant $(p=.052)$, while in Study 2 informant-reported actor extraversion did not predict self-reported sociable behavior. Furthermore, for Perspective 1 and 4 , some situation $\times$ extraversion interaction effects were only significant for informantreported actor extraversion. For Perspective 2 and 3 there were no differences regarding the interactions. However, contrasting the results of the aggregated extraversion score, self-reported partner extraversion was a significant predictor of interaction partnerreported sociable actor behavior (i.e., perceiver effects) in three of the four models, while the effects of informantreported partner extraversion were non-significant.

\section{Additional Files}

The additional files for this article can be found as follows:

$$
\begin{aligned}
& \text { - As supplemental material on our OSF page } \\
& \text { (osf.io/w96mv). }
\end{aligned}
$$

\section{Acknowledgements}

We are grateful to Ruben Arslan, Kathryn Bollich, Isabel Hartmann, Kelci Harris, Roos Hutteman, Josh Jackson, Pia Kampf, Albrecht Küfner, Carolin Landers, Ariane Liedmeier, Jana Mattern, Ina Mielke, Anissa Mike, Christian Pill, Julia Richter, Nicola Reckels, Jennifer Riefer, Lisa Schwalenstöcker, Brittany Solomon, and Sara Weston for their help with data collection, preparation, and documentation.

\section{Funding Information}

This research was supported by Grant BA 3731/6-1 from the German Research Foundation (DFG) to Mitja D. Back, Steffen Nestler, and Boris Egloff, and by Grant BCS1125553 from the National Science Foundation (USA) to Simine Vazire.

\section{Competing Interests}

The co-authors Simine Vazire (senior editor) and Mitja D. Back (editor) are also editors at Collabra: Psychology but did not play a role during the review process.

\section{Author Contributions}

- Contributed to conception and design: all authors

- Contributed to acquisition of data: SMB, REW, SV, MDB

- Contributed to analysis and interpretation of data: SMB, KG, SN, MDB

Drafted and/or revised the article: all authors

- Approved the submitted version for publication: all authors

\section{Author Information}

We embrace the values of openness and transparency in science (Schönbrodt, Maier, Heene, \& Zehetleitner, 2015; osf.io/4dvkw). We therefore follow the 21-word solution (Simmons, Nelson, \& Simmonsohn, 2012), or refer to complete project documentations in the OSF. There, we also publish all raw data necessary to reproduce reported results and provide scripts for all data analyses reported in this manuscript (osf.io/w96mv). We further acknowledge support by the Open Access Publication Fund of University of Muenster.

\section{References}

Ackerman, R. A., \& Corretti, C. A. (2015). Pathological personality traits and intimacy processes within roommate relationships. European Journal of Personality, 29(2), 152-172. DOI: https://doi. org/10.1002/per.1991

Asendorpf, J. B., Penke, L., \& Back, M. D. (2011). From dating to mating and relating: Predictors of initial and long-term outcomes of speed-dating in a community sample. European Journal of Personality, 25(1), 16-30. DOI: https://doi.org/10.1002/per.768

Baayen, R. H., Davidson, D. J., \& Bates, D. M. (2008). Mixed-effects modeling with crossed random 
effects for subjects and items. Journal of Memory and Language, 59(4), 390-412. DOI: https://doi. org/10.1016/j.jml.2007.12.005

Back, M. D. (2015). Opening the process black box: Mechanisms underlying the social consequences of personality. European Journal of Personality, 29(2), 91-96. DOI: https://doi.org/10.1002/per.1999

Back, M. D., Baumert, A., Denissen, J. J., Hartung, F. M., Penke, L., Schmukle, S. C., Schönbrodt, F. D., Schräder-Abé, M., Vollmann, M., Wagner, J., \& Wrzus, C. (2011). PERSOC: A unified framework for understanding the dynamic interplay of personality and social relationships. European Journal of Personality, 25(2), 90-107. DOI: https://doi. org/10.1002/per.811

Back, M. D., \& Egloff, B. (2009). Yes we can! A plea for direct behavioral observation in personality research. European Journal of Personality, 23(5), 403-405. DOI: https://doi.org/10.1002/per.725

Back, M. D., \& Kenny, D. A. (2010). The Social Relations Model: How to understand dyadic processes. Social and Personality Psychology Compass, 4(10), 855-870. DOI: https://doi. org/10.1111/j.1751-9004.2010.00303.x

Back, M. D., Schmukle, S. C., \& Egloff, B. (2009). Predicting actual behavior from the explicit and implicit self-concept of personality. Journal of Personality and Social Psychology, 97(3), 533-548. DOI: https://doi.org/10.1037/a0016229

Back, M. D., \& Vazire, S. (2012). Knowing our Personality. In: Vazire, S., \& Wilson, T. D. (Eds.), Handbook of Self Knowledge, 131-156. New York: Guilford Press

Back, M. D., \& Vazire, S. (2015). The social consequences of personality: Six suggestions for future research. European Journal of Personality, 29(2), 296-307. DOI: https://doi.org/10.1002/per.1998

Barrick, M. R., \& Mount, M. K. (1991). The Big Five personality dimensions and job performance: A Meta-Analysis. Personnel Psychology, 44(1), 1-26. DOI: https://doi.org/10.1111/j.1744-6570.1991. tb00688.x

Bates, D., Maechler, M., Bolker, B., Walker, S., Christensen, R. H. B., Singmann, H., Dai, B., Grothendieck, G., \& Green, P. (2018). Ime4: Linear mixed-effects models using 'Eigen' and S4. R package version, 1.1-17. Retrieved from: http://CRAN.R-project. org/package=lme4.

Beck, E. D., \& Jackson, J. J. (2018, February 21). Consistency and Change in Idiographic Personality: A Longitudinal ESM Network Study. DOI: https://doi. org/10.17605/OSF.IO/PB92Q

Beer, A., \& Watson, D. (2008). Personality judgment at zero acquaintance: Agreement, assumed similarity, and implicit simplicity. Journal of Personality Assessment, 90(3), 250-260. DOI: https://doi. org/10.1080/00223890701884970

Bleidorn, W. (2009). Linking personality states, current social roles and major life goals. European Journal of Personality, 23(6), 509-530. DOI: https://doi. org/10.1002/per.731
Bolger, N., Davis, A., \& Rafaeli, E. (2003). Diary methods: Capturing life as it is lived. Annual Review of Psychology, 54(1), 579-616. DOI: https://doi. org/10.1146/annurev.psych.54.101601.145030

Borkenau, P., Mauer, N., Riemann, R., Spinath, F. M., \& Angleitner, A. (2004). Thin slices of behavior as cues of personality and intelligence. Journal of Personality and Social Psychology, 86(4), 599-614. DOI: https:// doi.org/10.1037/0022-3514.86.4.599

Ching, C. M., Church, A. T., Katigbak, M. S., Reyes, J. A. S., Tanaka-Matsumi, J., Takaoka, S., Zhang, H., Shen, J., Arias, R. M., Rincon, B. C., \& Ortiz, F. A. (2014). The manifestation of traits in everyday behavior and affect: A five-culture study. Journal of Research in Personality, 48(1), 1-16. DOI: https://doi. org/10.1016/j.jrp.2013.10.002

Colman, D. E., Vineyard, J., \& Letzring, T. D. (2017). Exploring beyond simple demographic variables: Differences between traditional laboratory samples and crowdsourced online samples on the Big Five personality traits. Personality and Individual Differences. Advance online publication. DOI: https:// doi.org/10.1016/j.paid.2017.06.023

DeYoung, C. G., Quilty, L. C., \& Peterson, J. B. (2007). Between facets and domains: 10 aspects of the Big Five. Journal of Personality and Social Psychology, 93(5), 880-896. DOI: https://doi. org/10.1037/0022-3514.93.5.880

Diener, E., Larsen, R. J., \& Emmons, R. A. (1984). Person $\times$ situation interactions: Choice of situations and congruence response models. Journal of Personality and Social Psychology, 47(3), 580-592. DOI: https:// doi.org/10.1037/0022-3514.47.3.580

Eaton, L. G., \& Funder, D. C. (2003). The creation and consequences of the social world: An interactional analysis of extraversion. European Journal of Personality, 17(5), 375-395. DOI: https://doi.org/10.1002/ per.477

Edwards, T., \& Holtzman, N. S. (2017). A metaanalysis of correlations between depression and first person singular pronoun use. Journal of Research in Personality, 68, 63-68. DOI: https://doi.org/10.1016/j. jrp.2017.02.005

Emmons, R. A., \& Diener, E. (1986). Influence of impulsivity and sociability on subjective well-being. Journal of Personality and Social Psychology, 50(6), 1211-1215. DOI: https://doi. org/10.1037/0022-3514.50.6.1211

Endler, N. S., \& Edwards, J. M. (1986). Interactionism in personality in the twentieth century. Personality and Individual Differences, 7(3), 379-384. DOI: https:// doi.org/10.1016/0191-8869(86)90013-9

Endler, N. S., \& Magnusson, D. (1976). Toward an interactional psychology of personality. Psychological Bulletin, 83(5), 956-974. DOI: https://doi. org/10.1037/0033-2909.83.5.956

Finnigan, K. M., \& Vazire, S. (2017). The Incremental Validity of Average State Self-Reports Over Global Self-Reports of Personality. Journal of Personality and Social Psychology. Advance online 
publication. DOI: https://doi.org/10.1037/pspp00 00136

Fleeson, W. (2001). Toward a structure-and processintegrated view of personality: Traits as density distributions of states. Journal of Personality and Social Psychology, 80(6), 1011-1027. DOI: https://doi. org/10.1037/0022-3514.80.6.1011

Fleeson, W. (2007). Situation-based contingencies underlying trait-content manifestation in behavior. Journal of Personality, 75(4), 825-862. DOI: https:// doi.org/10.1111/j.1467-6494.2007.00458.x

Fleeson, W., \& Gallagher, M. P. (2009). The implications of Big Five standing for the distribution of trait manifestation in behavior: Fifteen experiencesampling studies and a meta-analysis. Journal of Personality and Social Psychology, 97(6), 1097-1114. DOI: https://doi.org/10.1037/a0016786

Fleeson, W., \& Jayawickreme, E. (2015). Whole trait theory. Journal of Research in Personality, 56(1), 82-92. DOI: https://doi.org/10.1016/j.jrp.2014.10.009

Fleeson, W., \& Law, M. K. (2015). Trait enactments as density distributions: The role of actors, situations, and observers in explaining stability and variability. Journal of Personality and Social Psychology, 109(6), 1090-1104. DOI: https://doi.org/10.1037/a0039517

Fleeson, W., \& Noftle, E. E. (2009). In: favor of the synthetic resolution to the person-situation debate. Journal of Research in Personality, 43(2), 150-154. DOI: https://doi.org/10.1016/j.jrp.2009.02.008

Foschi, R., \& Lauriola, M. (2014). Does sociability predict civic involvement and political participation? Journal of Personality and Social Psychology, 106(2), 339-357. DOI: https://doi.org/10.1037/a0035331

Funder, D. C. (2009). Persons, behaviors and situations: An agenda for personality psychology in the postwar era. Journal of Research in Personality, 43(2), 120-126. DOI: https://doi.org/10.1016/j.jrp.2008.12.041

Funder, D. C., \& Colvin, C. R. (1991). Explorations in behavioral consistency: Properties of persons, situations, and behaviors. Journal of Personality and Social Psychology, 60(5), 773-794. DOI: https://doi. org/10.1037/0022-3514.60.5.773

Gerlitz, J.-Y., \& Schupp, J. (2005). Zur Erhebung der Big-Five-basierten Persönlichkeitsmerkmale im SOEP. Dokumentation der Instrumentenentwicklung BFI-S auf Basis des SOEP-Pretests 2005 [The measurement of the Big Five personality traits in the SOEP]. Retrieved from DIW: http://www.diw.de/documents/ publikationen/73/diw_01.c.43490.de/rn4.pdf.

Geukes, K., Breil, S. M., Küfner, A., Hutteman, R., Nestler, S., \& Back, M. (2017, August 6). Explaining the Longitudinal Interplay of Personality and Social Relationships in the Laboratory and in the Field: The PILS and the CONNECT Study. DOI: https://doi. org/10.17605/OSF.IO/GNBM8

Geukes, K., Hutteman, R., Nestler, S., Küfner, A. C. P., \& Back, M. (2018, April 18). CONNECT. Retrieved from: osf.io/2pmcr.

Geukes, K., Nestler, S., Hutteman, R., Dufner, M., Küfner, A. C. P., Egloff, B., Denissen, J. J. A., \& Back, M. D. (2017). Puffed up but shaky selves: State self-esteem level and variability in narcissists. Journal of Personality and Social Psychology, 112(5), 769-786. DOI: https://doi.org/10.1037/pspp0000093

Geukes, K., Nestler, S., Hutteman, R., Küfner, A. C. P., \& Back, M. D. (2017). Trait personality and state variability: Predicting individual differences in within- and cross-context fluctuations in affect, selfevaluations, and behavior in everyday life. Journal of Research in Personality, 69, 124-138. DOI: https://doi. org/10.1016/j.jrp.2016.06.003

Gosling, S. D., John, O. P., Craik, K. H., \& Robins, R. W. (1998). Do people know how they behave? Selfreported act frequencies compared with online codings by observers. Journal of Personality and Social Psychology, 74(5), 1337-1349. DOI: https://doi. org/10.1037/0022-3514.74.5.1337

Graziano, W. G., Habashi, M. M., Sheese, B. E., \& Tobin, R. M. (2007). Agreeableness, empathy, and helping: A person $\times$ situation perspective. Journal of Personality and Social Psychology, 93(4), 583-599. DOI: https:// doi.org/10.1037/0022-3514.93.4.583

Haaland, S., \& Christiansen, N. D. (2002). Implications of trait-activation theory for evaluating the construct validity of assessment center ratings. Personnel Psychology, 55(1), 137-164. DOI: https://doi. org/10.1111/j.1744-6570.2002.tb00106.x

Harari, G. M., Lane, N., Wang, R., Crosier, B., Campbell, A. T., \& Gosling, S. D. (2016). Using smartphones to collect behavioral data in psychological science: Opportunities, practical considerations, and challenges. Perspectives on Psychological Science, 11(6), 838-854. DOI: https://doi.org/10.1177/1745691616650285

Heller, D., Komar, J., \& Lee, W. B. (2007). The dynamics of personality states, goals, and well-being. Personality and Social Psychology Bulletin, 33(6), 898-910. DOI: https://doi.org/10.1177/0146167207301010

Hogan, R. (2009). Much ado about nothing: The personsituation debate. Journal of Research in Personality, 43(2), 249. DOI: https://doi.org/10.1016/j. jrp.2009.01.022

Human, L. J., Carlson, E. N., Geukes, K., Nestler, S., \& Back, M. D. (in press). Do accurate personality impressions benefit early relationship development? The bidirectional associations between accuracy and liking. Journal of Personality and Social Psychology. DOI: https://doi.org/10.1037/pspp0000214

Humberg, S., Dufner, M., Schönbrodt, F. D., Geukes, K., Hutteman, R., Küfner, A. C. P., van Zalk, M. H. W., Denissen, J. J. A., Nestler, S., \& Back, M. D. (2018). Is accurate, positive, or inflated selfperception most advantageous for psychological adjustment? A competitive test of key hypotheses. Journal of Personality and Social Psychology. Advance online publication. DOI: https://doi.org/10.1037/ pspp0000204

Humberg, S., Dufner, M., Schönbrodt, F. D., Geukes, K., Hutteman, R., van Zalk, M. H. W., Denissen, J. J. A., Nestler, S., \& Back, M. D. (2018). Enhanced versus simply positive: A new condition-based regression analysis to disentangle effects of self-enhancement from effects of positivity of self-view. Journal of 
Personality and Social Psychology, 114(2), 303-322. DOI: https://doi.org/10.1037/pspp0000134

Hurtz, G. M., \& Donovan, J. J. (2000). Personality and job performance: The Big Five revisited. Journal of Applied Psychology, 85(6), 869-879. DOI: https://doi. org/10.1037/0021-9010.85.6.869

Ilmarinen, V. J., Vainikainen, M. P., Verkasalo, M., \& Lönnqvist, J. E. (2015). Why are extraverts more popular? Oral fluency mediates the effect of extraversion on popularity in middle childhood. European Journal of Personality, 29(2), 138-151. DOI: https://doi.org/10.1002/per.1982

Jackson, J. J., Wood, D., Bogg, T., Walton, K. E., Harms, P. D., \& Roberts, B. W. (2010). What do conscientious people do? Development and validation of the Behavioral Indicators of Conscientiousness (BIC). Journal of Research in Personality, 44(4), 501-511. DOI: https://doi.org/10.1016/j.jrp.2010.06.005

John, O. P., \& Robins, R. W. (1994). Accuracy and bias in self-perception: Individual differences in selfenhancement and the role of narcissism. Journal of Personality and Social Psychology, 66(1), 206-219. DOI: https://doi.org/10.1037/0022-3514.66.1.206

John, O. P., \& Srivastava, S. (1999). The Big Five trait taxonomy: History, measurement, and theoretical perspectives. In: Pervin, L. A., \& John, O. P. (Eds.), Handbook of personality: Theory and research, 2nd ed., 102-138. New York: Guilford Press.

Judd, C. M., Westfall, J., \& Kenny, D. A. (2012). Treating stimuli as a random factor in social psychology: A new and comprehensive solution to a pervasive but largely ignored problem. Journal of Personality and Social Psychology, 103(1), 54-59. DOI: https://doi. org/10.1037/a0028347

Judge, T. A., Simon, L. S., Hurst, C., \& Kelley, K. (2014). What I experienced yesterday is who I am today: Relationship of work motivations and behaviors to within-individual variation in the Five-Factor model of personality. Journal of Applied Psychology, 99(2), 199-221. DOI: https://doi.org/10.1037/a0034485

Kenny, D. A., Mohr, C. D., \& Levesque, M. J. (2001). A social relations variance partitioning of dyadic behavior. Psychological Bulletin, 127(1), 128-141. DOI: https://doi. org/10.1037/0033-2909.127.1.128

Kolar, D. W., Funder, D. C., \& Colvin, C. R. (1996). Comparing the accuracy of personality judgments by the self and knowledgeable others. Journal of Personality, 64(2), 311-337. DOI: https://doi. org/10.1111/j.1467-6494.1996.tb00513.x

Ksendzova, M., Iyer, R., Hill, G., Wojcik, S. P., \& Howell, R. T. (2015). The portrait of a hedonist: The personality and ethics behind the value and maladaptive pursuit of pleasure. Personality and Individual Differences, 79, 68-74. DOI: https://doi.org/10.1016/j. paid.2015.01.042

Kuznetsova, A., Brockhoff, P. B., \& Christensen, R. H. B. (2018). ImerTest: Tests in Linear Mixed Effects Models (lmer objects of lme4 package). R package Version 3.0-1. Retrieved from: http://CRAN.R-project.org/ package $=$ ImerTest.
Lakey, B. (2016). Understanding the Px S Aspect of Within-Person Variation: A Variance Partitioning Approach. Frontiers in Psychology, 7. DOI: https://doi. org/10.3389/fpsyg.2015.02004

Leckelt, M., Wetzel, E., Gerlach, T. M., Ackerman, R. A., Miller, J. D., Chopik, W. J., Back, M. D., et al. (2018). Validation of the Narcissistic Admiration and Rivalry Questionnaire Short Scale (NARQ-S) in convenience and representative samples. Psychological Assessment, 30(1), 86-96. DOI: https://doi.org/10.1037/ pas0000433

Lewin, K. (1951). Field theory in social science. New York: Harper.

Lievens, F., Chasteen, C. S., Day, E. A., \& Christiansen, N. D. (2006). Large-scale investigation of the role of Trait Activation Theory for understanding assessment center convergent and discriminant validity. Journal of Applied Psychology, 91(2), 247-258. DOI: https://doi. org/10.1037/0021-9010.91.2.247

Lucas, R. E., \& Diener, E. (2001). Understanding extraverts' enjoyment of social situations: The importance of pleasantness. Journal of Personality and Social Psychology, 81(2), 343-356. DOI: https:// doi.org/10.1037/0022-3514.81.2.343

Lucas, R. E., Le, K., \& Dyrenforth, P. S. (2008). Explaining the extraversion/positive affect relation: Sociability cannot account for extraverts' greater happiness. Journal of Personality, 76(3), 385-414. DOI: https:// doi.org/10.1111/j.1467-6494.2008.00490.x

McCabe, K. O., \& Fleeson, W. (2012). What is extraversion for? Integrating trait and motivational perspectives and identifying the purpose of extraversion. Psychological Science, 23(12), 1498-1505. DOI: https://doi. org/10.1177/0956797612444904

McCabe, K. O., \& Fleeson, W. (2016). Are traits useful? Explaining trait manifestations as tools in the pursuit of goals. Journal of Personality and Social Psychology, 110(2), 287-301. DOI: https://doi.org/10.1037/ a0039490

McCrae, R. R., \& Costa, P. T. (1987). Validation of the five-factor model of personality across instruments and observers. Journal of personality and social psychology, 52(1), 81-90. DOI: https://doi. org/10.1037/0022-3514.52.1.81

Mehl, M. R., Gosling, S. D., \& Pennebaker, J. W. (2006). Personality in its natural habitat: manifestations and implicit folk theories of personality in daily life. Journal of Personality and Social Psychology, 90(5), 862-867. DOI: https://doi.org/10.1037/0022-3514.90.5.862

Mehl, M. R., Pennebaker, J. W., Crow, D. M., Dabbs, J., \& Price, J. H. (2001). The Electronically Activated Recorder (EAR): A device for sampling naturalistic daily activities and conversations. Behavior Research Methods, Instruments, \& Computers, 33(4), 517-523. DOI: https://doi.org/10.3758/BF03195410

Miller, G. (2012). The smartphone psychology manifesto. Perspectives on Psychological Science, 7(3), 221-237. DOI: https://doi.org/10.1177/1745691612441215

Mischel, W., \& Shoda, Y. (1995). A cognitive-affective system theory of personality: Reconceptualizing situations, dispositions, dynamics, and 
invariance in personality structure. Psychological Review, 102(2), 246-268. DOI: https://doi. org/10.1037/0033-295X.102.2.246

Mischel, W., \& Shoda, Y. (2008). Towards a unified theory of personality: Integrating dispositions and processing dynamics within the cognitiveaffective processing system. In: John, O. P., Robins, R. W., \& Pervin, L. A. (Eds.), Handbook of personality psychology: Theory and research, 3rd ed., 208-241. New York: Guilford Press.

Nestler, S., \& Back, M. D. (2017). Using cross-classified structural equations models to examine the accuracy of personality judgments. Psychometrika, 82(2), 475-497. DOI: https://doi.org/10.1007/s11336-015-9485-6

Nestler, S., Geukes, K., \& Back, M. D. (2018). Modeling intraindividual variability in three-level models. Methodology, 14, 95-108. DOI: https://doi. org/10.1027/1614-2241/a000150

Nestler, S., Geukes, K., Hutteman, R., \& Back, M. D. (2017). Tackling longitudinal round-robin data: A Social Relations Growth Model. Psychometrika. 82(4), 1162-1181. DOI: https://doi.org/10.1007/ s11336-016-9546-5

Nezlek, J. B. (2011). Multilevel modeling for social and personality psychology. London, England: Sage Publications. DOI: https://doi. org/10.4135/9781446287996

Nezlek, J. B., \& Leary, M. R. (2002). Individual differences in self-presentational motives in daily social interaction. Personality and Social Psychology Bulletin, 28(2), 211-223. DOI: https://doi. org/10.1177/0146167202282007

Nezlek, J. B., Schütz, A., Schröder-Abé, M., \& Smith, C. V. (2011). A cross-cultural study of relationships between daily social interaction and the Five-Factor Model of personality. Journal of Personality, 79(4), 811-840. DOI: https://doi. org/10.1111/j.1467-6494.2011.00706.x

Noftle, E. E., \& Fleeson, W. (2010). Age differences in big five behavior averages and variabilities across the adult life span: moving beyond retrospective, global summary accounts of personality. Psychology and Aging, 25(1), 95-107. DOI: https://doi.org/10.1037/ a0018199

Oerlemans, W. G., \& Bakker, A. B. (2014). Why extraverts are happier: A day reconstruction study. Journal of Research in Personality, 50(1), 11-22. DOI: https://doi. org/10.1016/j.jrp.2014.02.001

Raudenbush, S. W., \& Bryk, A. S. (2002). Hierarchical linear models: Applications and data analysis methods (2nd ed.). Thousand Oaks, CA: Sage.

Rauthmann, J. F., Gallardo-Pujol, D., Guillaume, E. M., Todd, E., Nave, C. S., Sherman, R. A., Ziegler, M., Jones, A. B., \& Funder, D. C. (2014). The Situational Eight DIAMONDS: A taxonomy of major dimensions of situation characteristics. Journal of Personality and Social Psychology, 107(4), 677-718. DOI: https://doi. org/10.1037/a0037250

Rauthmann, J. F., \& Sherman, R. A. (2016a). Measuring the Situational Eight DIAMONDS characteristics of situations: An optimization of the RSQ-8 to the S8*. European Journal of Psychological Assessment, 32(2), 155-164. DOI: https://doi.org/10.1027/1015-5759/ a000246

Rauthmann, J. F., \& Sherman, R. A. (2016b). Ultra-brief measures for the Situational EightDIAMONDS domains. European Journal of Psychological Assessment, 32(2), 165-174. DOI: https://doi.org/10.1027/1015-5759/ a000245

Rauthmann, J. F., Sherman, R. A., \& Funder, D. C. (2015). Principles of situation research: Towards a better understanding of psychological situations. European Journal of Personality, 29(3), 363-381. DOI: https:// doi.org/10.1002/per.1994

Reis, H. T., \& Wheeler, L. (1991). Studying social interaction with the Rochester Interaction Record. In: Berkowitz, L. (Ed.), Advances in experimental social psychology, 24, 269-318. San Diego, CA: Academic Press. DOI: https://doi.org/10.1016/ S0065-2601(08)60332-9

Schaffhuser, K., Allemand, M., \& Martin, M. (2014). Personality traits and relationship satisfaction in intimate couples: Three perspectives on personality. European Journal of Personality, 28(2), 120-133. DOI: https://doi.org/10.1002/per.1948

Schmid-Mast, M., Gatica-Perez, D., Frauendorfer, D., Nguyen, L., \& Choudhury, T. (2015). Social sensing for psychology: Automated interpersonal behavior assessment. Current Directions in Psychological Science, 24(2), 154-160. DOI: https://doi. org/10.1177/0963721414560811

Schönbrodt, F. D., Maier, M., Heene, M., \& Zehetleitner, M. (2015). Voluntary commitment to research transparency. Retrieved from: http://www. researchtransparency.org.

Sekara, V., Stopczynski, A., \& Lehmann, S. (2016). Fundamental structures of dynamic social networks. Proceedings of the National Academy of Sciences, 113(36), 9977-9982. DOI: https://doi.org/10.1073/ pnas. 1602803113

Sherman, R. A., Rauthmann, J. F., Brown, N. A., Serfass, D. G., \& Jones, A. B. (2015). The independent effects of personality and situations on real-time expressions of behavior and emotion. Journal of Personality and Social Psychology, 109(5), 872-888. DOI: https://doi. org/10.1037/pspp0000036

Simmons, J. P., Nelson, L. D., \& Simonsohn, U. (2012). A 21 word solution. Retrieved from: http://ssrn.com/ abstract=2160588. DOI: https://doi.org/10.2139/ ssrn. 2160588

Slatcher, R. B., \& Vazire, S. (2009). Effects of global and contextualized personality on relationship satisfaction. Journal of Research in Personality, 43(4), 624-633. DOI: https://doi.org/10.1016/j.jrp.2009.02.012

Snyder, M., \& Ickes, W. (1985). Personality and social behavior. In: Lindzey, G., \& Aronson, E. (Eds.), Handbook of social psychology, $3^{\text {rd }}$ ed., 883-947. New York: Random House.

Solomon, B. C., \& Vazire, S. (2014). You are so beautiful... to me: Seeing beyond biases and achieving accuracy 
in romantic relationships. Journal of Personality and Social Psychology, 107(3), 516-528. DOI: https://doi. org/10.1037/a0036899

Srivastava, S., Angelo, K. M., \& Vallereux, S. R. (2008). Extraversion and positive affect: A day reconstruction study of person-environment transactions. Journal of Research in Personality, 42(6), 1613-1618. DOI: https:// doi.org/10.1016/j.jrp.2008.05.002

Sun, J., Schwartz, H. A., Son, Y., Kern, M. L., \& Vazire, S. (2018). The language of well-being: Tracking withinperson emotion fluctuations through everyday speech. Manuscript submitted for publication.

Sun, J., \& Vazire, S. (2018). Do people know what they're like in the moment? Manuscript submitted for publication.

Ten Berge, M. A., \& De Raad, B. (2002). The structure of situations from a personality perspective. European Journal of Personality, 16(2), 81-102. DOI: https://doi. org/10.1002/per.435

Tett, R. P., \& Burnett, D. D. (2003). A personality traitbased interactionist model of job performance. Journal of Applied Psychology, 88(3), 500-517. DOI: https:// doi.org/10.1037/0021-9010.88.3.500

Tett, R. P., \& Guterman, H. A. (2000). Situation trait relevance, trait expression, and cross-situational consistency: Testing a principle of trait activation. Journal of Research in Personality, 4(34), 397-423. DOI: https://doi.org/10.1006/jrpe.2000.2292

Vater, A., \& Schröder-Abé, M. (2015). Explaining the link between personality and relationship satisfaction: Emotion regulation and interpersonal behaviour in conflict discussions. European Journal of Personality, 29(2), 201-215. DOI: https://doi.org/10.1002/ per.1993

Vazire, S. (2010). Who knows what about a person? The self-other knowledge asymmetry (SOKA) model. Journal of Personality and Social Psychology, 98(2), 281-300. DOI: https://doi.org/10.1037/ a0017908

Vazire, S., \& Mehl, M. R. (2008). Knowing me, knowing you: The accuracy and unique predictive validity of self-ratings and other-ratings of daily behavior. Journal of Personality and Social Psychology, 95(5), 1202-1216. DOI: https://doi.org/10.1037/a0013314

Vazire, S., Wilson, R. E., Solomon, B., Bollich, K., Harris, K., Weston, S., Mike, A., \& Jackson, J. J. (2015). Personality and interpersonal roles (PAIRS). Study in progress.

Visser, B. A., \& Pozzebon, J. A. (2013). Who are you and what do you want? Life aspirations, personality, and well-being. Personality and Individual Differences, 54(2), 266-271. DOI: https://doi.org/10.1016/j. paid.2012.09.010
Wagerman, S. A., \& Funder, D. C. (2009). Situations. In: Corr, P. J., \& Mathews, G. (Eds.), Cambridge handbook of personality, 27-42. Cambridge, England: University Press. DOI: https://doi.org/10.1017/ CB09780511596544.005

Waterman, A. S. (2005). When effort is enjoyed: Two studies of intrinsic motivation for personally salient activities. Motivation and Emotion, 29(3), 165-188. DOI: https://doi.org/10.1007/s11031-005-9440-4

Watson, D., Clark, L. A., McIntyre, C. W., \& Hamaker, S. (1992). Affect, personality, and social activity. Journal of Personality and Social Psychology, 63(6), 1011-1025. DOI: https://doi.org/10.1037/0022-3514.63.6.1011

Wheeler, L., \& Nezlek, J. (1977). Sex differences in social participation. Journal of Personality and Social Psychology, 35(10), 742-754. DOI: https://doi. org/10.1037/0022-3514.35.10.742

Wilson, G. D., \& Brazendale, A. H. (1973). Social attitude correlates of Eysenck's personality dimensions. Social Behavior and Personality: an International Journal, 1(2), 115-118. DOI: https://doi.org/10.2224/ sbp.1973.1.2.115

Wilson, R. E., Harris, K., \& Vazire, S. (2015). Personality and friendship satisfaction in daily life: Do everyday social interactions account for individual differences in friendship satisfaction? European Journal of Personality, 29(2), 173-186. DOI: https://doi. org/10.1002/per.1996

Wilson, R. E., Thompson, R. J., \& Vazire, S. (2017). Are fluctuations in personality more than just fluctuations in affect? Journal of Research in Personality, 69, 110-123. DOI: https://doi. org/10.1016/j.jrp.2016.06.006

Wilt, J., Noftle, E. E., Fleeson, W., \& Spain, J. S. (2012). The dynamic role of personality states in mediating the relationship between extraversion and positive affect. Journal of Personality, 80(5), 1205-1236. DOI: https://doi. org/10.1111/j.1467-6494.2011.00756.x

Wood, D., Harms, P., \& Vazire, S. (2010). Perceiver effects as projective tests: what your perceptions of others say about you. Journal of Personality and Social Psychology, 99(1), 174-190. DOI: https://doi.org/10.1037/ a0019390

Wrzus, C., \& Mehl, M. (2015). Lab and/or field? Measuring personality processes and their social consequences. European Journal of Personality, 29(2), 250-271. DOI: https://doi.org/10.1002/per.1986

Zhang, J. W., \& Howell, R. T. (2011). Do time perspectives predict unique variance in life satisfaction beyond personality traits? Personality and Individual Differences, 50(8), 1261-1266. DOI: https://doi. org/10.1016/j.paid.2011.02.021 
Peer review comments

The author(s) of this paper chose the Open Review option, and the peer review comments are available at: http://doi.org/ 10.1525/collabra.170.pr

How to cite this article: Breil, S. M., Geukes, K., Wilson, R. E., Nestler, S., Vazire, S., \& Back, M. D. (2019). Zooming into Real-Life Extraversion - how Personality and Situation Shape Sociability in Social Interactions. Collabra: Psychology, 5(1): 7. DOI: https://doi. org/10.1525/collabra.170

Senior Editor: M. Brent Donnellan

Editor: M. Brent Donnellan

Submitted: 23 May 2018 Accepted: 16 December 2018 Published: 16 January 2019

Copyright: $\odot 2019$ The Author(s). This is an open-access article distributed under the terms of the Creative Commons Attribution 4.0 International License (CC-BY 4.0), which permits unrestricted use, distribution, and reproduction in any medium, provided the original author and source are credited. See http://creativecommons.org/licenses/by/4.0/. 